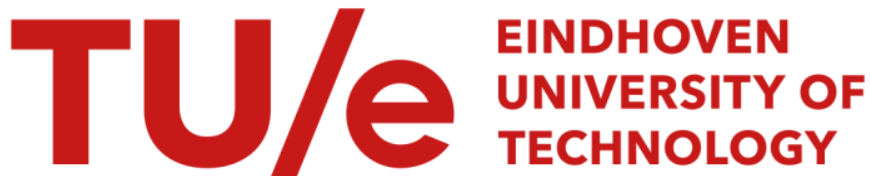

\section{Expulsion of Entrapped Air in a Rapidly Filling Horizontal Pipe}

\section{Citation for published version (APA):}

Zhou, L., Cao, Y., Karney, B., Bergant, A., Tijsseling, A. S., Liu, D., \& Wang, P. (2020). Expulsion of Entrapped Air in a Rapidly Filling Horizontal Pipe. Journal of Hydraulic Engineering, 146(7), [04020047].

https://doi.org/10.1061/(ASCE)HY.1943-7900.0001773

\section{Document license: \\ TAVERNE}

DOI:

10.1061/(ASCE)HY.1943-7900.0001773

Document status and date:

Published: 01/07/2020

\section{Document Version:}

Publisher's PDF, also known as Version of Record (includes final page, issue and volume numbers)

\section{Please check the document version of this publication:}

- A submitted manuscript is the version of the article upon submission and before peer-review. There can be important differences between the submitted version and the official published version of record. People interested in the research are advised to contact the author for the final version of the publication, or visit the $\mathrm{DOI}$ to the publisher's website.

- The final author version and the galley proof are versions of the publication after peer review.

- The final published version features the final layout of the paper including the volume, issue and page numbers.

Link to publication

\section{General rights}

Copyright and moral rights for the publications made accessible in the public portal are retained by the authors and/or other copyright owners and it is a condition of accessing publications that users recognise and abide by the legal requirements associated with these rights.

- Users may download and print one copy of any publication from the public portal for the purpose of private study or research.

- You may not further distribute the material or use it for any profit-making activity or commercial gain

- You may freely distribute the URL identifying the publication in the public portal.

If the publication is distributed under the terms of Article 25fa of the Dutch Copyright Act, indicated by the "Taverne" license above, please follow below link for the End User Agreement:

www.tue.nl/taverne

Take down policy

If you believe that this document breaches copyright please contact us at:

openaccess@tue.nl

providing details and we will investigate your claim. 


\title{
Expulsion of Entrapped Air in a Rapidly Filling Horizontal Pipe
}

\author{
Ling Zhou ${ }^{1}$; Yun Cao ${ }^{2}$; Bryan Karney, M.ASCE${ }^{3}$; Anton Bergant, Ph.D. ${ }^{4}$; \\ Arris S. Tijsseling; ${ }^{5}$ Deyou Liu'; and Pei Wang ${ }^{7}$
}

\begin{abstract}
Air expulsion from an end-of-pipe orifice in a rapidly filling horizontal pipe is investigated experimentally and analytically in order to more completely characterize the system's transient response. In particular, images of air-water patterns, air-volume variations, orifice flow regimes, and measured pressure histories are synchronized to elucidate the process of air expulsion. Air expulsion typically undergoes an early stage involving pressurization, expansion, and release of a portion of the initial air, events that generally occur even before the advancing water column reaches the pipe end. The next stage depends strongly on the orifice size. For a small discharge orifice, an oscillation of the residual air occurs with the discharge orifice being intermittently choked by water; by contrast, larger discharge orifices rapidly and completely expelled the air, often leading to high water-hammer pressures. Three distinct patterns of pressure oscillation are typically observed. With small orifices, the cushioning effect of the initial air tends to dominate, whereas slightly larger orifices lead to a more complex process of expulsion and more persistent and larger pressure oscillations. Even larger orifices often lead to severe water-hammer pressures. Thus, smaller orifices tend to result in smaller pressure fluctuations. As expected, both the initial-air volume and the inlet pressure significantly influence the transient response. A derived analytical model accurately captures the measured pressure oscillations during the intermittent release of residual air, including the water hammer that can arise due to suddenly arresting the liquid water column.
\end{abstract} DOI: 10.1061/(ASCE)HY.1943-7900.0001773. ㅇ 2020 American Society of Civil Engineers.

Author keywords: Transient flow; Pipeline; Trapped air; Air expulsion; Orifice.

\section{Introduction}

Hydraulic failures in urban stormwater systems, whether manhole cover blow-off, geysers, combined-sewer overflows, or local flooding, are both distressing and distressingly common (Zhou et al. 2002a; Wright et al. 2011). The associated transient responses and failure mechanisms tend to be complex and difficult to predict. Previous studies (Zhou et al. 2002a; Wright et al. 2011; Bergant

${ }^{1}$ Professor, College of Water Conservancy and Hydropower Engineering, Hohai Univ., 1 Xikang Rd., Nanjing 210098, China (corresponding author). ORCID: https://orcid.org/0000-0002-1750-6126. Email: zlhhu@ 163.com

${ }^{2} \mathrm{Ph} . \mathrm{D}$. Candidate, College of Water Conservancy and Hydropower Engineering, Hohai Univ., 1 Xikang Rd., Nanjing 210098, China. ORCID: https://orcid.org/0000-0002-3313-713X. Email: 1754398324@qq.com

${ }^{3}$ Professor, Dept. of Civil Engineering, Univ. of Toronto, 35 St. George St., Toronto, ON, Canada M5S 1A4. Email: karney@ecf.utoronto.ca

${ }^{4} \mathrm{Head}$, Dept. of Applied Research and Computations, Litostroj Power d. o.o., Litostrojska 50, Ljubljana 1000, Slovenia; Faculty of Mechanical Engineering., Univ. of Ljubljana, Aškerčeva 6, Ljubljana 1000, Slovenia. Email: anton.bergant@litostrojpower.eu

${ }^{5}$ Associate Professor, Dept. of Mathematics and Computer Science, Eindhoven Univ. of Technology, P.O. Box 513, Eindhoven, MB 5600, Netherlands. Email: a.s.tijsseling@tue.nl

${ }^{6}$ Professor, College of Water Conservancy and Hydropower Engineering, Hohai Univ., 1 Xikang Rd., Nanjing 210098, China. Email: liudyhhuc@163.com

${ }^{7}$ Associate Professor, College of Energy and Electrical Engineering, Hohai Univ., 1 Xikang Rd., Nanjing 210098, China. Email: franciswp2012@163.com

Note. This manuscript was submitted on March 19, 2019; approved on January 24, 2020; published online on April 30, 2020. Discussion period open until September 30, 2020; separate discussions must be submitted for individual papers. This paper is part of the Journal of $\boldsymbol{H y}$ draulic Engineering, (C) ASCE, ISSN 0733-9429. et al. 2018) indicated that large pressure surges induced by air entrapment and release (air expulsion) often play a crucial role in how these events unfold.

Several researchers have investigated air expulsion from an orifice in a filling pipe system. Albertson and Andrews (1971) reported that rapid air expulsion from an air-release valve may cause dangerous transient pressures in the filling pipeline. Martin and Lee (2000, 2012) and Lee (2005) experimentally investigated rapid air expulsion from eight different-sized orifices in a horizontal pipe. They found that the critical orifice size is approximately $d / D=$ 0.19 , where $d$ and $D$ are the diameters of the orifice and the pipe, resulting in peak pressures up to nearly five times the upstream head. Importantly, they also pointed out that for medium orifice sizes (around the critical values $d / D=0.13,0.19$, and 0.25 ), the maximum pressure is often associated with rapid compression of the small remaining amount of air rather than a traditional pure liquid water-hammer impact.

Similarly, Zhou et al. (2002a, b) observed three types of pressure-oscillation patterns in a rapidly filling horizontal pipe with entrapped air, involving 12 orifice sizes. For small orifices $(d / D<0.086)$, the air cushioning effect is significant (Type 1$)$. When the orifice is large $(d / D>0.2)$, water-hammer pressures dominate (Type 3 ). For intermediate orifice sizes (with $d / D$ ranging from 0.086 to 0.2 ), the air cushioning effect is intermediate and the water-hammer effect is mitigated (Type 2). The highest peak pressures up to 15 times the upstream head were observed at a critical orifice size around $d / D=0.2$. Interestingly, for medium orifice sizes near the critical value, the explanation of Zhou et al. (2002a, b) that the impacting water hammer causes the pressure peaks is notably different from the "rapid air compression" arguments of Martin and Lee (2000, 2012) and Lee (2005). Bucur et al. (2017) confirmed that two pressure-oscillation patterns similar to the Types 1 and 3 of Zhou et al. (2002a) occur in their rapid- 


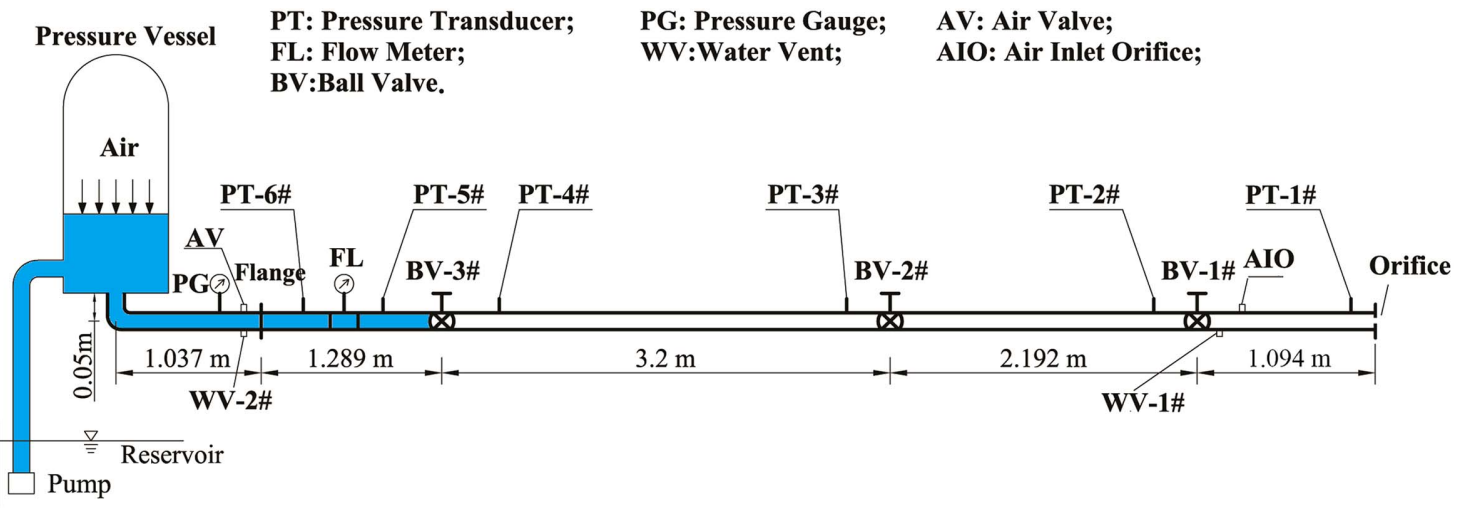

Fig. 1. Schematic of experimental apparatus on air expulsion in a horizontal pipe.

filling horizontal-pipeline experiments with five different orifice sizes. Zhou et al. (2019) observed only two pressure-oscillation patterns with the characteristics of initial-air cushioning effect and water-hammer effect during the rapid expulsion in the filling of a vertical pipe.

Martin (1976) pioneered a rigid water-column model to simulate the transient pressures in a rapidly filling pipeline. Subsequently, Martin (1976)'s model was improved by considering the impacting water hammer, the changing water-column length, water compressibility, and residual air (Zhou et al. 2002a; Lee 2005; Martin and Lee 2012; Tijsseling et al. 2019; Zhou et al. 2019). Moreover, Li and Zhu (2018) and Zhou et al. (2018) employed three-dimensional computational fluid dynamics (CFD) to simulate air-water transients in a rapidly filling pipeline. It is worth mentioning that large ratios of inlet pressure to pipe diameter $\left(P_{r} / D\right)$ are also found in previous experimental works, such as $P_{r}=343,275,206$, and $137 \mathrm{kPa}$ for $D=0.035 \mathrm{~m}$ of Zhou et al. (2002a), and $P_{r}=300,200$, and $100 \mathrm{kPa}$ for $D=0.026 \mathrm{~m}$ of Lee (2005) and Martin and Lee (2012). Related numerical research has indicated that rapid filling often occurs at relative low ratios of inlet pressure to pipe diameter, especially in stormwater systems (Wright et al. 2011).

These studies collectively suggest that the transient flow mechanisms associated with air expulsion are complex and that the dynamic response is, as expected, sensitive to pipe profile and orifice size. Significantly, however, for medium orifice sizes near the critical $d / D$ value in a horizontal pipe, the explanations of Zhou et al. (2002a, b) differ from those of Martin and Lee $(2000,2012)$ and Lee (2005), thus creating a need to better understand the effect of the size of the air-releasing orifice on the transient pressure, particularly the quantification of air volume during the process of compression/expansion and air expulsion. The interplay between the liquid water and the air-water interactions during compression and expulsion are obviously central to sort out the physical processes. Thus, the synchronous relation between the transient pressures and the air-water interaction during the rapid air expulsion is of great interest.

This paper focuses on rapid air expulsion in a horizontal pipe over a refined $d / D$ range to better explore this transient behavior. In particular, high-resolution photographs of the airwater flow pattern, air-volume variation, and orifice flow regime are synchronized here along with the recorded pressure histories in order to illustrate their interrelations and to compare the results with previous work. Moreover, a new analytical model is developed to predict the intermittent release of residual air and the impacting water hammer in order to independently confirm the experimental analysis.

\section{Experimental Investigation}

\section{Description of Test Facility and Instrumentation}

Experiments involving the rapid expulsion of air from a waterfilling horizontal pipeline were conducted at Hohai University, China. The test system consists of an underground reservoir, a submersible pump, a pressure vessel, three manually operated onequarter-turn ball valves distributed along the horizontal pipeline, and a changeable orifice at the pipe's end (Fig. 1). The orifice consists of a central circular hole of $10 \mathrm{~mm}$ depth with sharp edges. The 8.862-m-long and 40.0-mm-internal-diameter pipeline connecting the upstream pressure vessel to the end orifice is part stainless-steel pipe (1.087-m length and 5.0-mm wall thickness) and part transparent Plexiglas polymethylmethacrylate pipe (7.775-m length and 10.0-mm wall thickness). An upstream 750-L VAREM bladder pressure vessel (VAREM Company, Padova, Italy) provides a nearly constant inlet pressure with a preset pressure that can range from 0 to $1.0 \mathrm{MPa}$. Three ball valves (BV-1 to $\mathrm{BV}-3)$ are used to form three initial-air column lengths, with the air initially contained at atmospheric pressure between one closed ball valve and the pipe's downstream end. The No. 1 water vent and air inlet valve between Ball valve 1 and pipe end are used only to drain the water. During the filling experiments, both the water vent and air inlet valve remain fully closed.

Six piezoelectric pressure transducers (Model M20X1.5, Benya Technology, Nanjing, China) are installed along the pipeline at distances of $1.387,1.956,2.786,5.264,7.458$, and $8.797 \mathrm{~m}$ downstream of the pressure vessel. All transducers have a scale from 0 to $5,000 \mathrm{kPa}$ with a frequency response exceeding $10 \mathrm{kHz}$; voltage output ranges from 2 to $10 \mathrm{~V}$ direct current (DC); linearity and lag error range from $0.03 \%$ to $0.3 \%$ of the full range. An electromagnetic flowmeter (Benya Technology, Nanjing, China) is installed $1.587 \mathrm{~m}$ downstream of the reservoir to measure steady flow rates ranging from 0 to $25 \mathrm{~m}^{3} / \mathrm{h}$, and a voltage output ranging from 1 to $5 \mathrm{~V} \mathrm{DC}$. The maximum error is $0.2 \%$ of the full range.

A fast-response data-acquisition system records transient voltages of the flow rate and the six pressures. The seven signals are fed into a National Instruments 16-bit acquisition data (A-D) card (Model PCI 6221, Shanghai NI Instruments, Shanghai, China), the rate of which is as much as 250,000 samples per second between -10 and $+10 \mathrm{~V}$. In these fast-transient experiments, data are recorded at 2,000 readings per second. A high-speed, high-resolution digital camera (Phantom 500D, Vision Research, Wayne, New Jersey) records transient events in the transparent pipe at more than 10,000 frames per second. Image processing software (e.g., Photoshop version CS6 and MATLAB version 9.0) was used to analyze the high-resolution air-water interaction images. 


\section{Experimental Tests}

Specific test conditions used three inlet pressures $\left(P_{r}=0.08,0.12\right.$, and $0.16 \mathrm{MPa})$, three initial-air lengths $\left(L_{a 0}=1.058,3.25\right.$, and $6.45 \mathrm{~m}$, thereby considering the small amount of air entrapped inside the ball valve), and 21 orifice sizes ( $d=0,1,1.5,2,2.5,3,3.5$, $4,4.5,5,6,7,8,9,10,12,14,16,18,20$, and $24 \mathrm{~mm})$. Thus, a total of 189 different test cases were examined, with each test repeated at least three times. The water wave speed in the Plexiglas pipe was measured between 800 and $850 \mathrm{~m} / \mathrm{s}$ during the rapid valve-closure tests with no air. The net friction factor under steady-flow conditions, $f$, based on measured head values, ranged from 0.03 to 0.08 . The high loss factor is caused by the three ball valves, the flow meter, and the 16 flanges with eight rubber gaskets (losses due to possible extrusion deformation).

The orifice discharge coefficient was determined under steady flow conditions, $C_{d}=0.6$ to 0.82 . Filling events are initiated manually by the rapid opening of the one-quarter-turn ball valve. Highspeed digital camera data showed that the valve opening time (from fully closed to fully open) ranged from 0.07 to $0.1 \mathrm{~s}$.

\section{Experimental Observations and Results}

Observations indicate that transient events during rapid filling of the horizontal pipeline undergo an initial Stage 1 involving the compression, expansion, and release of air through the orifice, all of which occur before the water column reaches the pipe's end flange. If the discharge orifice is small, Stage 2(a) involves oscillation of the residual air as the orifice was intermittently choked by water (a broken air-water interface and discrete air bubbles/pockets being observed). Larger orifices tend to result in a sudden pressurization and water-hammer spikes as the trapped air is rapidly expelled from the pipeline [Stage 2(b)].

The characteristics of different stages are associated with the orifice size. Generally, when the orifice is relatively small, Stage 1 dominates, and the maximum pressure caused by the air compression and cushioning effects occurs in this stage, which for this case is more severe than that in the Stage 2(a) with residual air. With slightly larger orifices, the residual air in Stage 2(a) often results in a longer and more dramatic pressure oscillation than those occurring in Stage 1. When the orifice size is further increased, the air effects are mitigated or vanish entirely, and the water-hammer pressure in Stage 2(b) dominates; that is, the entrapped air is often expelled quickly with a short air compression-expansion process; subsequently, a high water-hammer pressure occurs when the water column impacts the pipe end. Moreover, the distinct sound of air exhausting from the orifice, as well as the subsequent sound of water impact, were clearly heard in the experiments, especially when intermediate-size orifices were used.

Correspondingly, it is found that maximum pressures during the whole transient process were associated with at least one of the following mechanisms: (1) when compression of the initialair volume occurs before the liquid water reaches the pipe end, (2) when the residual air is compressed after the orifice is choked by water, or (3) when the advancing water column impacts the pipe end. Therefore, three different types of pressure-oscillation patterns are defined in this study, namely Type 1 behavior, in which the initial-air cushioning effect is dominant; Type 2 behavior, in which the residual-air effect becomes significant; and Type 3 behavior, in which the pure liquid water-hammer effect is dominant.

The high-speed high-resolution camera was used to observe the events at the pipe section from BV-1 to the end orifice (Fig. 1). Importantly, the transient-air volume and the flow regime at the orifice during the rapid filling can be obtained by processing the air-water interaction high-quality images. The camera images revealed five flow regimes under the different filling events: (I) air expulsion, (II) water being expelled, (III) water with little air, (IV) mist flow, and (V) air admission through the orifice. To elaborate on the behavior of the three different types, pressure oscillations, air-water interaction images, transient-air void fractions (ratio of air volume $\forall_{a}$ to pipe volume capacity $\forall, \forall_{a} / \forall$ ), and flow regimes at the end orifice are synchronously analyzed. Each pattern is discussed subsequently.

\section{Type 1 Behavior: Dominant Initial-Air Cushioning Effect}

Type 1 behavior always occurs when the orifice is closed or tiny. Fig. 2 displays a series of air-void fractions, orifice flow regimes, and the synchronous pressure variations (measured at PT-1) to illustrate the air expulsion behavior during the filling process. Here, $d / D=0.025$ (small orifice size), $L_{a 0} / L=\forall_{a 0} / \forall=11.9 \%$, $H_{r}^{*} / H_{\mathrm{atm}}^{*}=2.18$, and time represents the interval since valve opening.

As portrayed in Fig. 2, the sequence of events during the air release is as follows:

1. The initial condition imposes the value of tank pressure head $H_{r}^{*}$, which is present as far as the closed Ball valve 1 , and the initial-air volume at atmospheric pressure $H_{\mathrm{atm}}^{*}$ is present between BV-1 and the pipe-end orifice [Fig. 2(a)].

2. When the valve is opened, because the entrapped air is first compressed by the accelerating water column, the air volume is compressed and air pressure rises [Fig. 2(b)]. In Flow regime $\mathrm{I}$, air is expelled at the end orifice until the filling water column reaches the pipe end.

3. The pressure and volume of entrapped air simultaneously reach their maximum and minimum value before the filling water column reaches to the pipe end [Fig. 2(c)]; moreover, the airwater interface is notably inclined, with the water velocity near the pipe bottom being the greatest due its greater pressure, stratifying the flow.

4. The upper water begins to flow back to the upstream end due to the air expansion [in Fig. 2(d)]. Meanwhile, the end orifice is choked by water because the stratified water near the pipe bottom still moves toward the pipe end. Interestingly, the water impacting the pipe end does not lead to an obvious pressure increase, as shown in Fig. 2(g), and the obvious explanation is that the cushioning air effect is great enough to prevent a high impact pressure.

5. The air pressure falls to a low value as the residual-air volume expands to its peak value, while a large quantity of air-water mixture gathers near the pipe end and the orifice is still choked by water [Fig. 2(e)].

6. The result of these processes is typically several compressionexpulsion-expansion rounds, with the residual air intermittently expelled through the orifice. A detailed transient flow representation, including the pressure and volume of residual air and flow regimes at the end orifice, is displayed in Fig. 2(f). After several seconds, the whole system quickly reaches a near-steady flow but with some residual-air pockets/bubbles entrapped near the top of the pipe.

Overall, in Type 1 behavior, rapid air release is delayed, and the transient is initially dominated by an air compression-expulsionexpansion stage, with eventually water impacting onto the pipe end, followed by a residual-air compression-expulsion-expansion stage. During the whole rapid filling process, the water front is relatively free of entrained air, and the expulsion of air is intermittent. Once the bottom water moves to the pipe end, the flow at the end orifice 


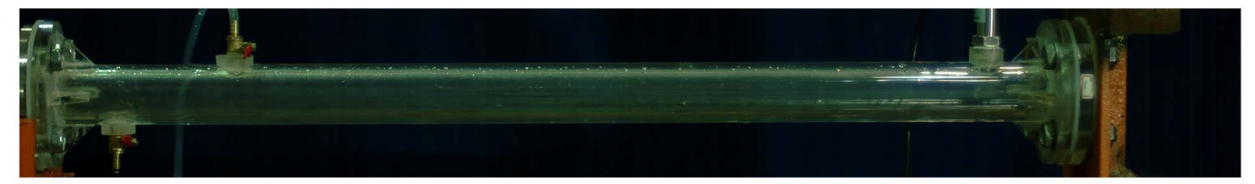

(a)

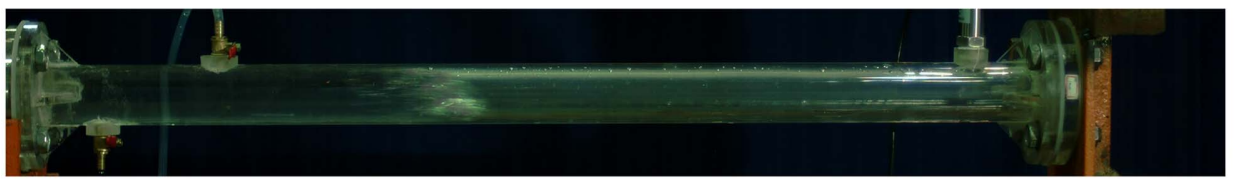

(b)

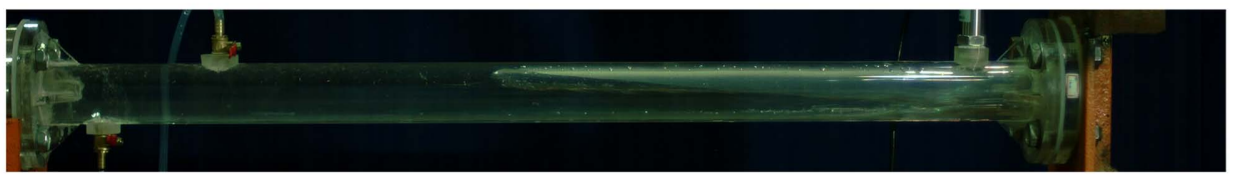

(c)

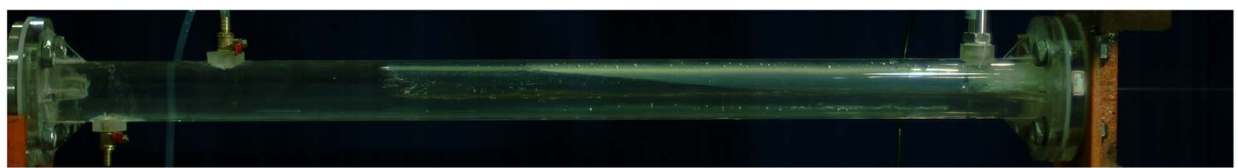

(d)

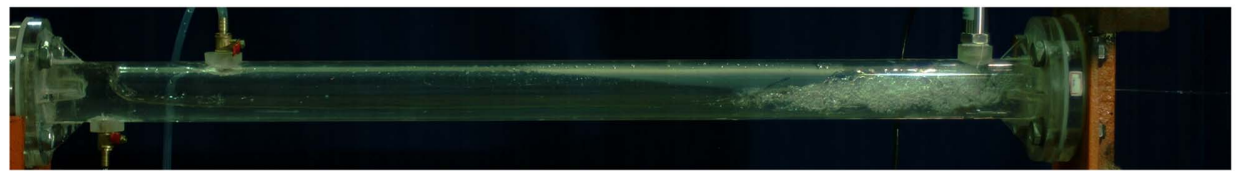

(e)

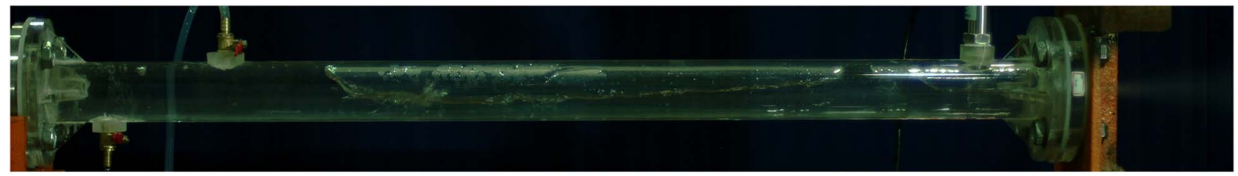

(f)

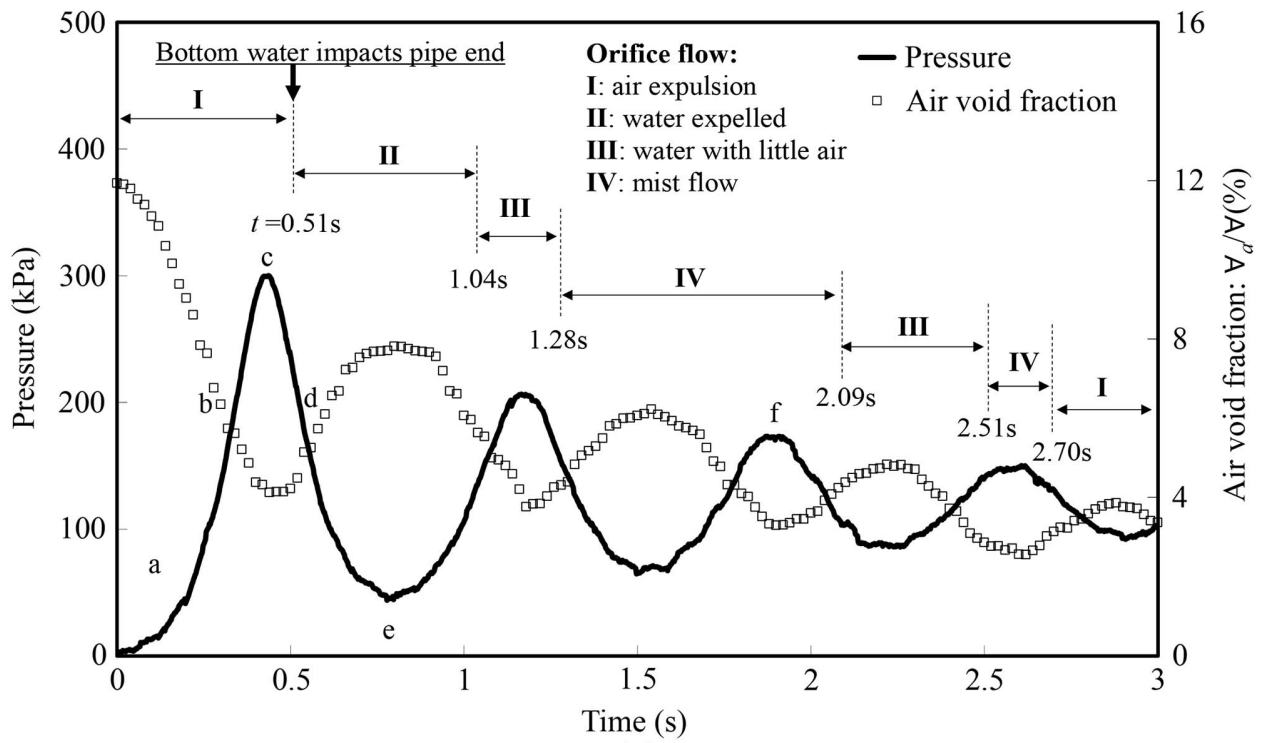

(g)

Fig. 2. Air-water pattern and transient pressure of Type 1 behavior during little air expulsion $\left(d / D=0.025, L_{a 0} / L=11.9 \%\right.$, and $\left.H_{r}^{*} / H_{\mathrm{atm}}^{*}=2.18\right)$ : (a) $t=0 \mathrm{~s}$; (b) $t=0.27 \mathrm{~s}$; (c) $t=0.44 \mathrm{~s}$; (d) $t=0.52 \mathrm{~s}$; (e) $t=0.80 \mathrm{~s}$; (f) $t=1.90 \mathrm{~s}$; and (g) pressure oscillations at PT-1. 
becomes complex, involving the alternate occurrence of four flow regimes: (II) water expelled, (III) water with little air, (IV) mist flow, and (I) air expulsion [Fig. 2(g)]. Because the air volume responds directly to the prevailing pressure, the maximum pressure occurs during the first compression of the initial air. For Type 1 behavior, the upper limit of the orifice size ratio, $d / D$, is less than 0.075 for the great majority of the tests conducted in this work. However, as the inlet pressure and air length increase, the upper limit value may reach up to $d / D=0.0875$.

\section{Type 2 Behavior: Dominant Residual-Air Effect}

In Type 2 behavior, residual-air effects with slightly larger orifices play a more dominant role. Figs. 3 and 4 illustrate the Type 2 behavior of rapid air expulsion by displaying a series of air void fractions (but without this in Fig. 4 because long initial air is out of the camera shooting range), orifice flow regimes, and the synchronous pressure variations (measured at PT-1). In Fig. 3, $d / D=0.0875, L_{a 0} / L=\forall_{a 0} / \forall=11.9 \%$, and $H_{r}^{*} / H_{\mathrm{atm}}^{*}=2.18$; in Fig. $4, d / D=0.0875, L_{a 0} / L=\forall_{a 0} / \forall=72.8 \%$, and $H_{r}^{*} / H_{\mathrm{atm}}^{*}=$ 2.18. Comparison of Figs. 3 and 4 shows the effect of initial-air length.

The sequence of events in Fig. 3 indicates that in Type 2 behavior the rapid air release undergoes three distinct phases. First, there is an initial-air compression-expulsion stage occurring even before the water reaches the pipe-end orifice. During this state, only air is expelled as the air volume decreases along with an increase in the air pressure [Figs. 3(a and h)]. After this, water impacts the pipe end, choking the end orifice; however, water continues to fill along the top of the pipe with an associated decrease in air volume and increase in air pressure [Fig. 3(h)]. Finally, the third stage involves a compression-expulsion-expansion of the residual air: after the bottom water moves to the pipe end, complicated and alternate flows arise at the end orifice, containing three flow regimes: Flow regime II with water being expelled, Flow regime III with water expulsion and some air, and finally Flow regime IV, mist flow [Figs. 3(c-g)].

As the filling event progresses, the air pressure and air volume more closely obey the ideal gas rule [Fig. 3(h)], in which the air pressure increases (decreases) with the decrease (increase) of the air volume. However, the highest peak is due to the residual-air compression, not due to the initial-air compression or the water impacting on the pipe end. Moreover, a large pressure increase is observed after each pulse. Interestingly, the pressure oscillation in Fig. 3(h) is significantly different from that in Fig. 2(g), although the recorded air-water profiles and the basic air-release processes are similar in Figs. 3(a-g) and 2(a-f).

Importantly, the maximum pressure in Fig. 3 is higher than that in Fig. 2. One physical interpretation is that the maximum pressure caused by the entrapped air compression is markedly associated with the residual-air void fraction (the ratio of the residual-air volume to the whole capacity of the pipeline). Zhou et al. (2013b) demonstrated that for rapid pipe filling without air release, as the initial-air void fraction (i.e., $\forall_{a 0} / \forall$ ) decreases, the maximum pressure first increases and then decreases, with the most dangerous initial-air length occurring when about $3.4 \%$ of the pipeline is initially occupied by air. As shown in Figs. 3(b and h), the residualair void fraction is approximately $1.5 \%$ at the maximum pressure. According to the ideal gas rule [Eq. (1)], with $k=1.4$

$$
H_{a 0}^{*} \cdot \forall_{a 0}^{k}=H_{a}^{*} \cdot \forall_{a}^{k}
$$

The corresponding initial-air void fraction $\left(L_{a 0} / L\right)$ is near $4.8 \%$, which is not too far from the critical value $(3.4 \%)$. Therefore, the pressure peak caused by the residual-air compression in
Fig. 3(h) is much higher than those due to initial-air and residualair compression in Fig. 2(g).

Similarly, Fig. 4 shows the Type 2 behavior with a longer initial-air column. The transient flow undergoes a short initialair compression-expulsion-expansion stage [Figs. 4(a and b)]; then, water impacts the pipe end (still without obvious pressure increase [Fig. 4(c)], followed by a long residual-air compression-expulsionexpansion stage [Figs. 4(d-k)]. As shown in Fig. 4(1), the residualair pressure peaks (Points $\mathrm{d}, \mathrm{f}, \mathrm{h}$, and $\mathrm{j}$, for example)] are much higher than the initial-air pressure peak (Point b); in particular, the maximum pressure (Point $\mathrm{j}$ ) occurs in the fourth round of the residual-air oscillation. The main reason for this was previously identified as "the maximum pressure peak decreases as air void fraction ( $\forall a / \forall$ is gradually deviated from the critical value $3.4 \%$ )" (Zhou et al. 2013b). It can be seen in Fig. 4 that the residual-air void fractions are far less than the initial value due to the huge air expulsion before the water reaches to the pipe end, and the residual-air void fraction in Fig. 4(j) is the closest to the critical value $(3.4 \%)$.

Generally, in Type 2 behavior, the dominating residual-air effect leads to complex pressure oscillations even as stratification leads to intermittent periods of air expulsion. The maximum pressure may arise at the first residual-air stage or any other subsequent residualair stage, depending on the exact details of the filling sequence and on the residual-air void fraction. Particularly, a residual-air void fraction close to the critical value of the initial-air void fraction may lead to a high-pressure peak, which can be much more dangerous than the initial-air effect occurring before the water reaches to the pipe end. However, some common characteristics of Types 1 and 2 behaviors are observed, including the irregular air-water interfaces, the intermittent air-releases, and the maximum pressures due to the air-compression effect. The possible range of the orifice size ratio, $d / D$, for Type 2 behavior is from 0.075 to 0.15 for all tests conducted in this work. As the inlet pressure and initial-air length increase, both the upper and lower limit values may slightly deviate because the residual-air effect is sensitive to the flow conditions.

\section{Type 3 Behavior: Impacting Water-Hammer Effect Dominated}

Type 3 behavior arises when the discharge orifice is large enough to allow for the complete expulsion of the initial air in one pulse (or perhaps two pulses), so that the air cushioning effect is negligible. Fig. 5 shows air void fractions, orifice flow regimes, and the associated pressure variations for the case of large air release (Type 3 behavior). Here, $d / D=0.175, L_{a 0} / L=\forall_{a 0} / \forall=11.9 \%$, and $H_{r}^{*} / H_{\text {atm }}^{*}=2.18$.

The end orifice is now large though that the entrapped air is quickly expelled from the end orifice. However, during this stage, the air pressure and volume still obey the ideal gas rule [Fig. 5(g)], and thus the air pressure naturally slightly increases with the decrease of the air volume. Subsequently, the water column slams onto the pipe end, inducing a water-hammer-type pressure rise [Figs. 5(b and g)]. During this experimental test, it was observed that the entire experimental apparatus was jarred, and a loud water slamming sound was heard, which were clear indications of the high impact pressure. Interestingly, after the water impacted onto the pipe end, the reflected wave caused the water column to flow backward [Fig. 5(c)], inducing air admission through the end orifice, as shown in Figs. 5(d and g).

When the inverse flow turns to positive flow, the water column impacts onto the pipe end again [Fig. 5(e)]. This second waterhammer pressure is much higher than the maximum pressure caused by the air effects in Types 1 and 2 behaviors, although it 


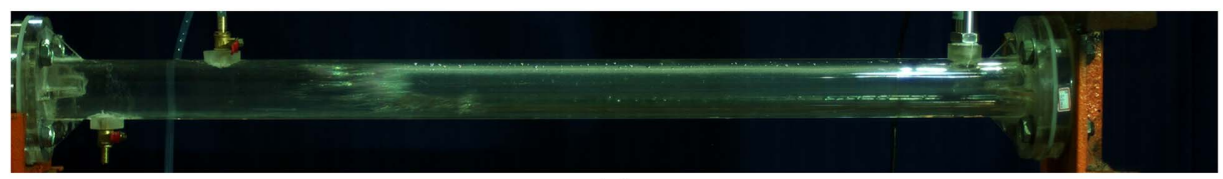

(a)

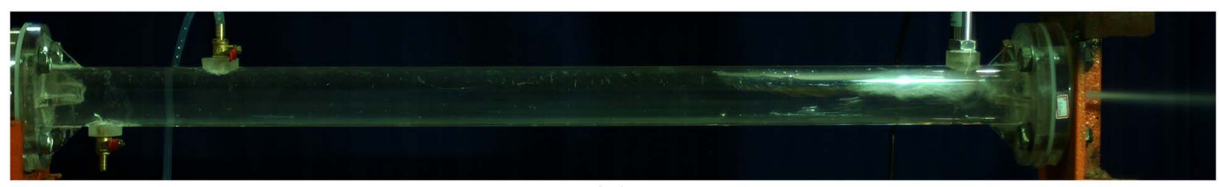

(b)

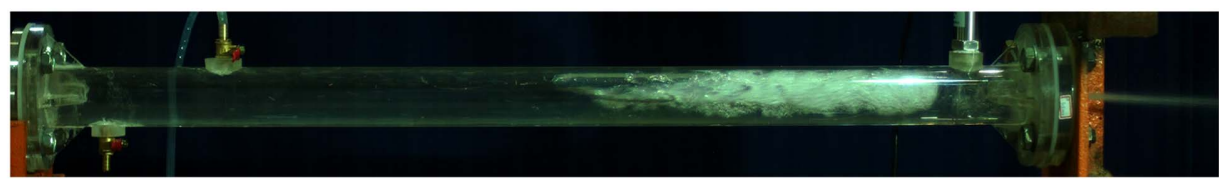

(c)

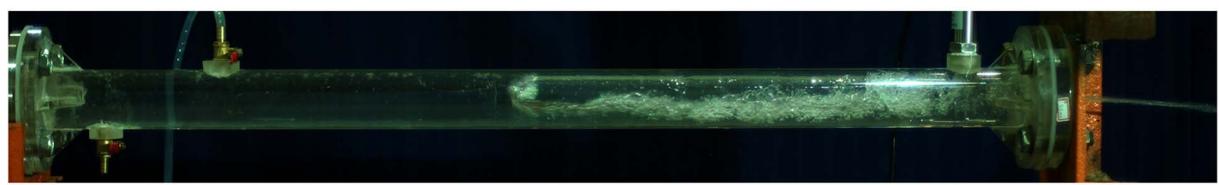

(d)

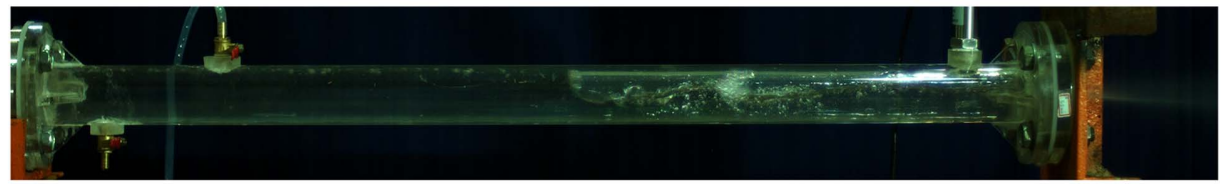

(e)

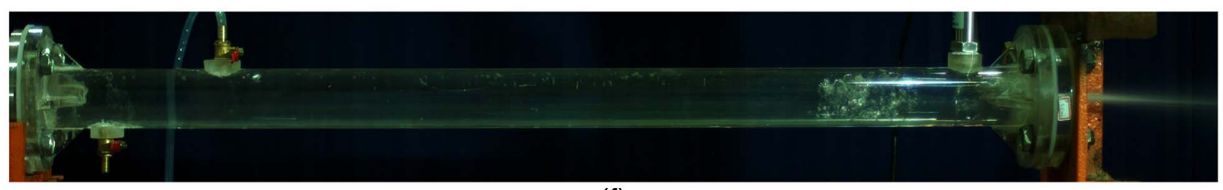

(f)

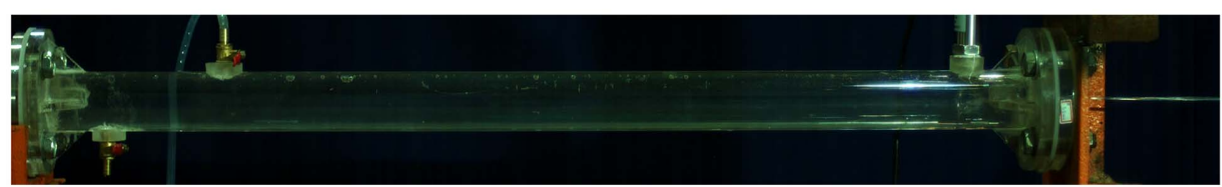

(g)

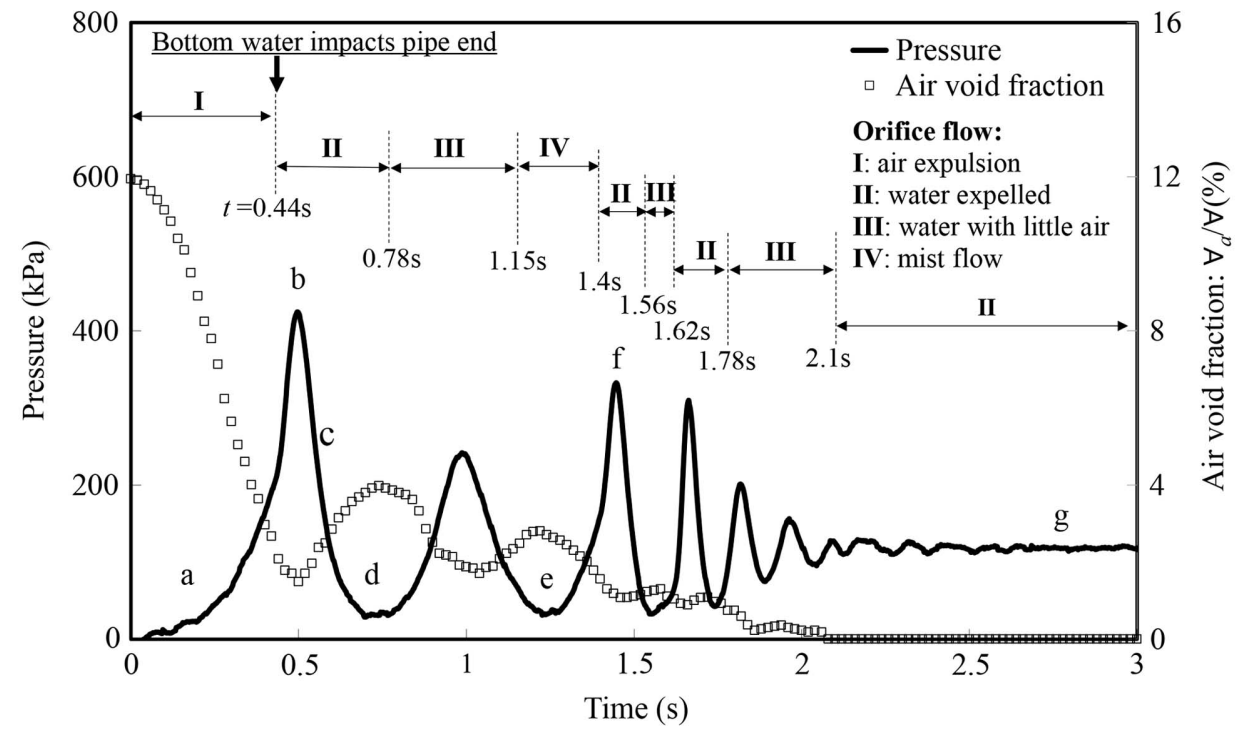

(h)

Fig. 3. Air-water pattern and transient pressure of Type 2 behavior with short entrapped air $\left(d / D=0.0875, L_{a 0} / L=11.9 \%\right.$, and $\left.H_{r}^{*} / H_{\mathrm{atm}}^{*}=2.18\right)$ : (a) $t=0.25 \mathrm{~s}$; (b) $t=0.50 \mathrm{~s}$; (c) $t=0.60 \mathrm{~s}$; (d) $t=0.74 \mathrm{~s}$; (e) $t=1.25 \mathrm{~s}$; (f) $t=1.45 \mathrm{~s}$; (g) $t=2.84 \mathrm{~s}$; and (h) pressure oscillations at PT-1. 


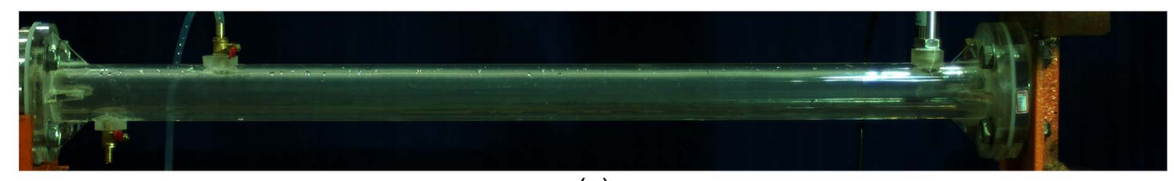

(a)

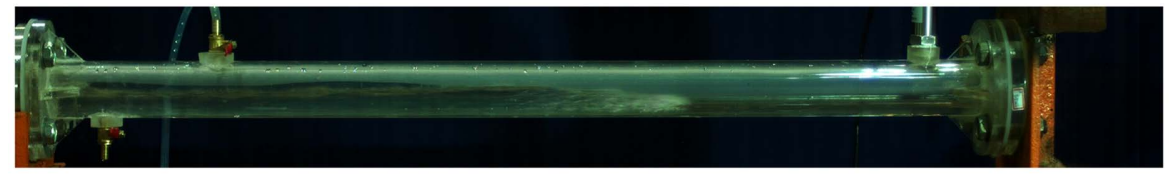

(b)

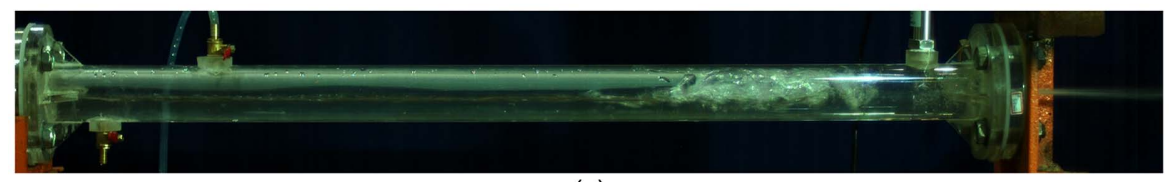

(c)

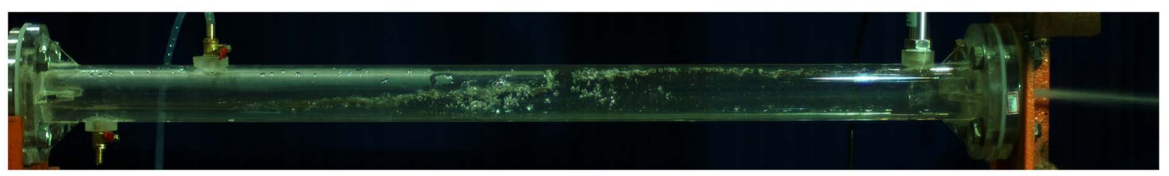

(d)

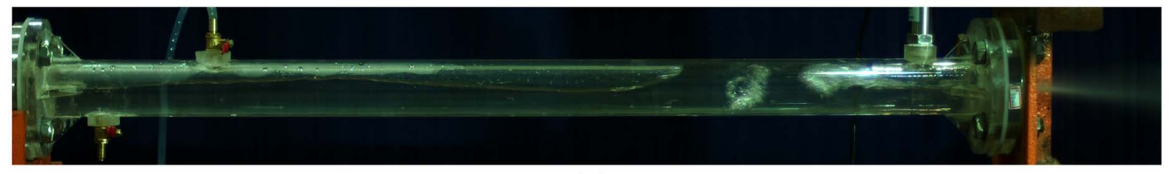

(e)

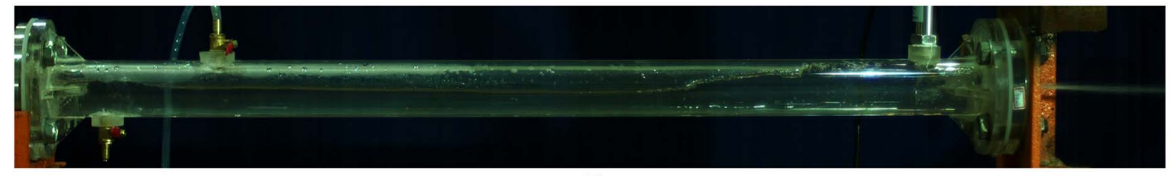

(f)

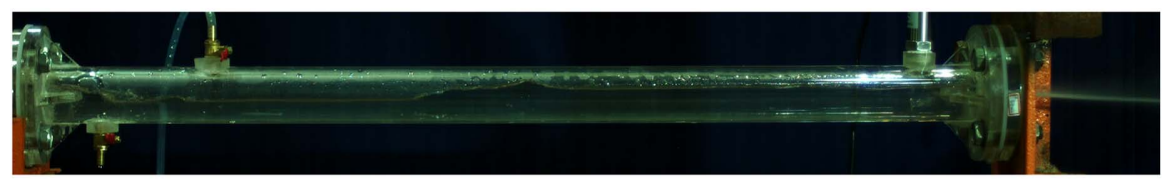

(g)

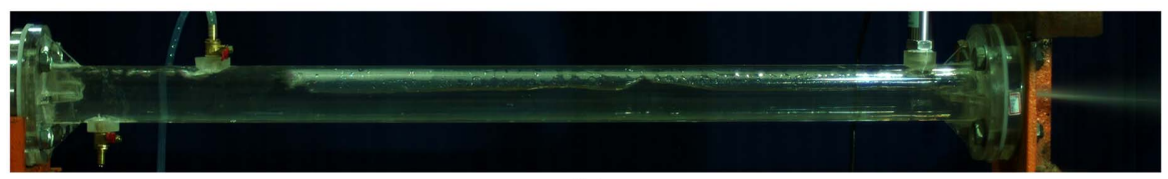

(h)

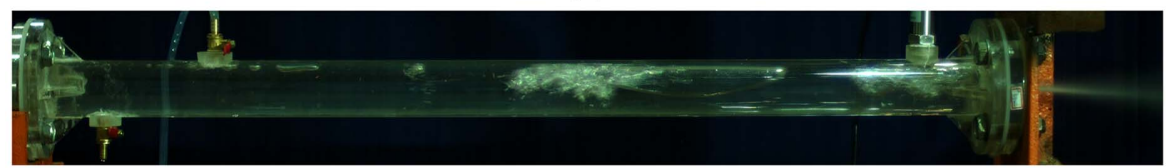

(i)

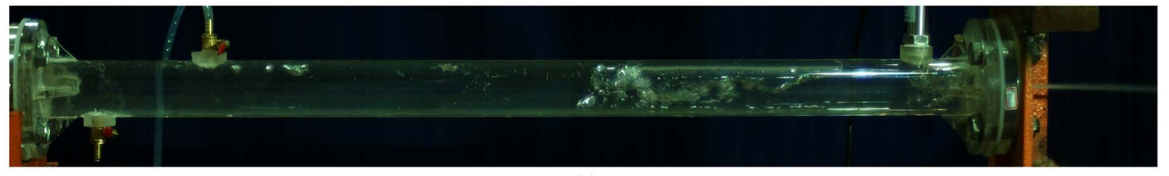

(j)

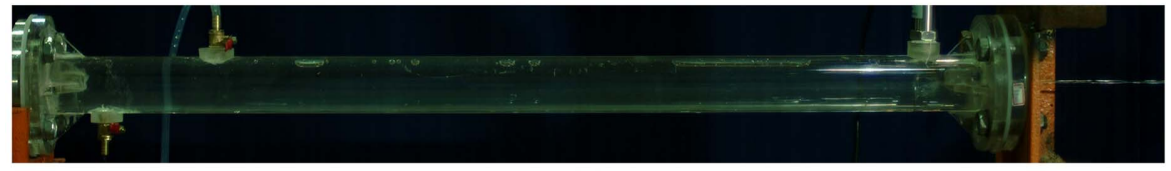

(k)

Fig. 4. Air-water pattern and transient pressure of Type 2 behavior with long entrapped air $\left(d / D=0.0875, L_{a 0} / L=72.8 \%\right.$, and $\left.H_{r}^{*} / H_{\mathrm{atm}}^{*}=2.18\right)$ : (a) $t=0 \mathrm{~s}$; (b) $t=1.25 \mathrm{~s}$; (c) $t=2.08 \mathrm{~s}$; (d) $t=2.35 \mathrm{~s}$; (e) $t=4.72 \mathrm{~s}$; (f) $t=5.02 \mathrm{~s}$; (g) $t=6.56 \mathrm{~s}$; (h) $t=6.74 \mathrm{~s}$; (i) $t=7.62 \mathrm{~s}$; (j) $t=7.72 \mathrm{~s}$; (k) $t=10.42 \mathrm{~s}$; and (l) pressure oscillations at PT-1. 


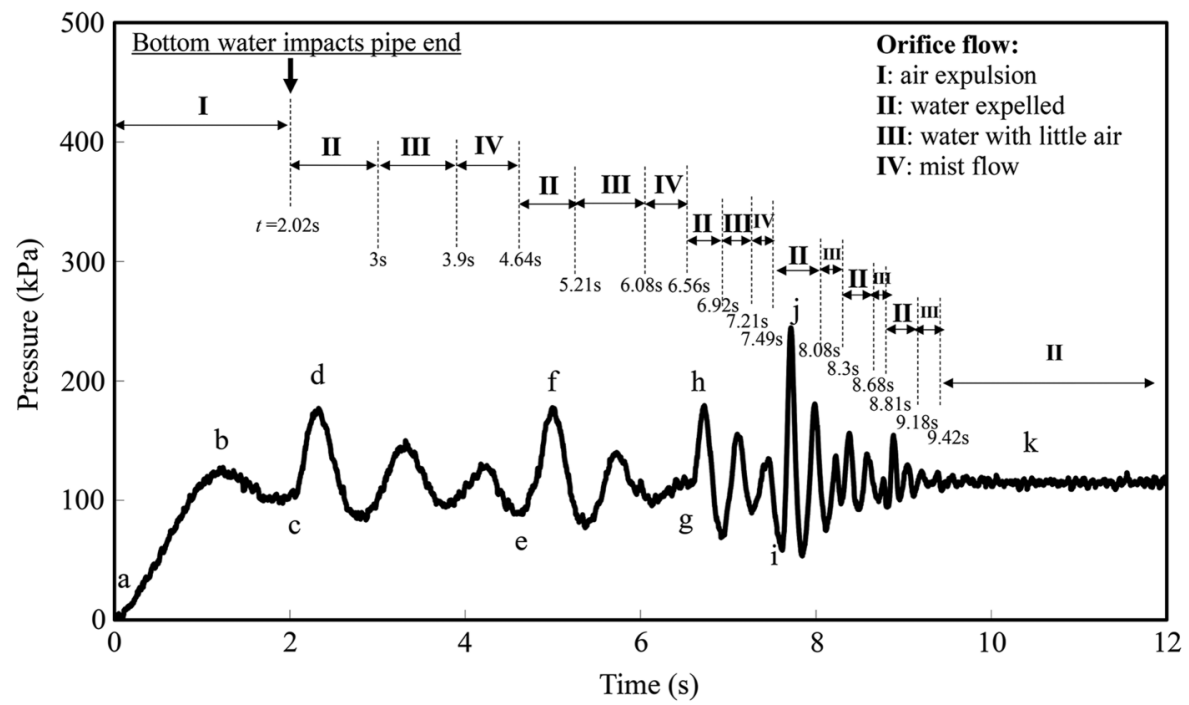

(l)

Fig. 4. (Continued.)

is far less than the first water-hammer pressure [Figs. 5(b and g)]. After all the air is expelled through the orifice, the flow and pressures become essentially steady [Figs. 5(f and g)]. Observations from other experiments indicate that as the orifice size slightly increases, both the reverse flow and secondary impact pressure disappear.

In Type 3 behavior, the water-hammer impact is dominant, and the maximum pressure can be up to nine times the inlet pressure, which is much higher than those in Types 1 and 2 behaviors (with maximum pressures less than four times the inlet pressure). Unlike the small or intermediate air-release situations in Types 1 and 2 behaviors, the pressure rise is sharp and the pressure attenuation is rapid (within $0.5 \mathrm{~s}$ here); there is no obvious air trapped on top of the flow, and almost all of the air is released from the orifice by the time that the water column reaches the pipe end. The orifice size ratio, $d / D$, for Type 3 behavior is larger than 0.15 for all of the systems tested in this work. As the inlet pressure and initial-air length change, the critical values may go down to 0.10 . Table 1 summarizes the range of the three types of behaviors and the general features of the pressure-oscillation patterns for different orifice sizes in this experimental study.

\section{Effect of Orifice Size on the Maximum Pressure Magnitude}

All of the measured maximum peak pressures during the rapid filling were examined as a function of orifice size and grouped into three types, i.e., Types $1-3$. Figs. 6(a-c) give the relation between the maximum pressure and the orifice size for different initial-air lengths and inlet pressures.

Generally, for Type 1 behavior, the maximum pressure originates from the initial-air compression, and ranges between 1.1 and 2.0 times the inlet pressure in this experimental work. As shown in Figs. 6(a-c), the maximum pressure slightly decreases with increase of the orifice size. Small orifices may provide crucial pressure relief, yielding peak pressures even less than cases with no air expulsion.

For Type 2 behavior, the highest pressures caused by the compression of the residual air can be up to four times the inlet pressure. Some results in Figs. 6(a-c) show that the data scatter is large and that there is no clear systematic relationship between the orifice size and peak pressure. The main reason is that for Type 2 behavior, due to complex mixing of the residual-air bubble and intermittent expulsion of the residual air, the peak pressure and orifice size do not follow a smooth variation.

For Type 3 behavior, the maximum pressures due to waterhammer impact were observed to be up to nine times the inlet pressure. These maximum pressures increase sharply with a slight increase of the orifice size up to the most dangerous peak near the critical value of $d / D$ (ranging from 0.175 to 0.225 ). After this, maximum pressures gradually decrease for the larger orifice sizes. This behavior depends on two factors: the impacting velocity and the orifice size (as indicated by the continuity and momentum equations at the orifice in the "Impacting Pressure Stage (Type 3)" section). When the orifice size is less than the critical value of $d / D$, the air cushioning effect decreases rapidly with increases in orifice size, resulting in a higher impact velocity and larger pressures. However, when the orifice size is larger than the critical value of $d / D$, the air cushion gradually reduces to zero, so that the effect of the orifice size on the impact velocity can be neglected. When this occurs, the orifice acts as a constant-pressure outlet for the air; for the water, a larger orifice size results in a lower impacting pressure.

\section{Effects of Inlet Pressure and Air Length on the Maximum Pressure Magnitude}

The maximum pressure is quite sensitive to the parameters of the pipe system. The effects of the driving pressure and initial-air length are discussed next.

Figs. $7(\mathrm{a}-\mathrm{c})$ give the magnitude of the peak pressure as function of initial-air length $\left(L_{a 0} / L\right)$ for the current set of tests, where $H_{r}^{*} / H_{\mathrm{atm}}^{*}=2.18$. Fig. 7(a) shows that for Type 1 behavior, the maximum pressure increases as the initial-air volume decreases because of the diminishing air cushioning effect. For Type 2 behavior [Fig. 7(b)], as the initial-air length decreases, the maximum pressures first decrease or decrease slightly and then increase quite sharply. For Type 3 behavior, the experiments show that when the orifice size is less than the critical value $(d / D<0.2)$, the maximum pressures increase with decreases in air content. Once the orifice size is larger than the critical value $(d / D>0.2)$, the maximum pressure first increases and then decreases (or levels out) as the initial-air length decreases.

The explanation is that for a given not-too-large orifice size, the water-hammer impact pressures mainly depend on the impact 


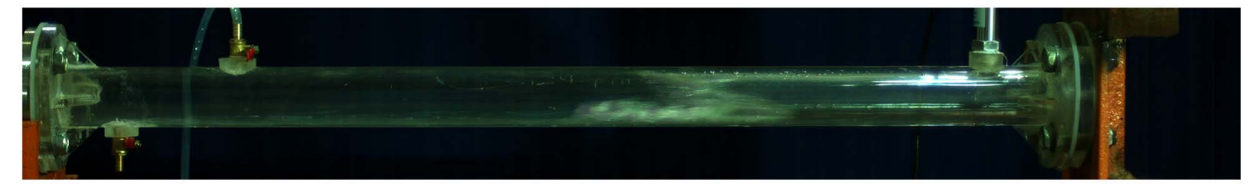

(a)

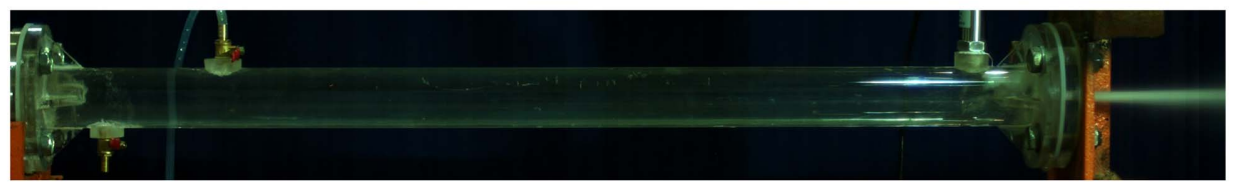

(b)

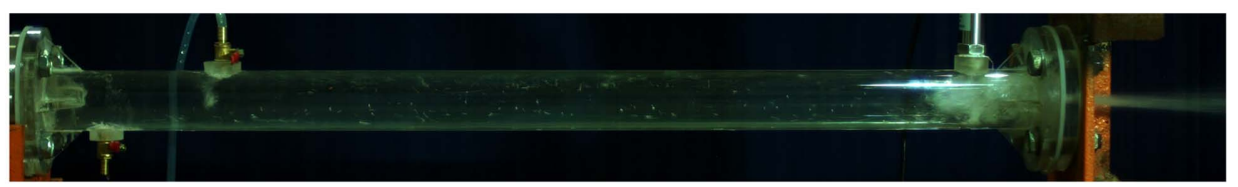

(c)

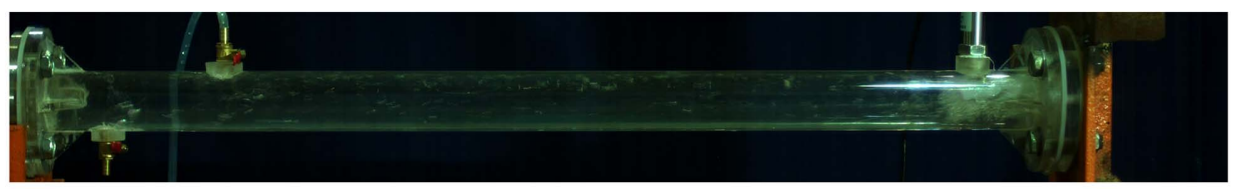

(d)

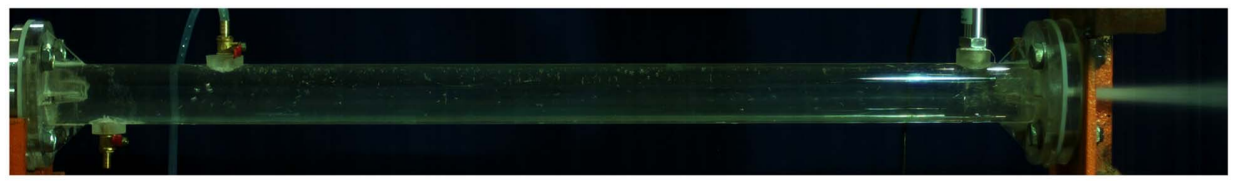

(e)

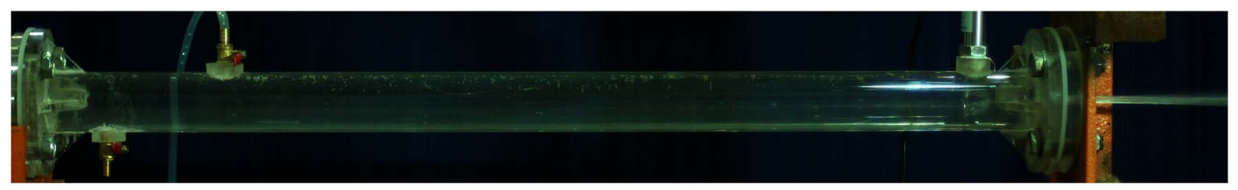

(f)

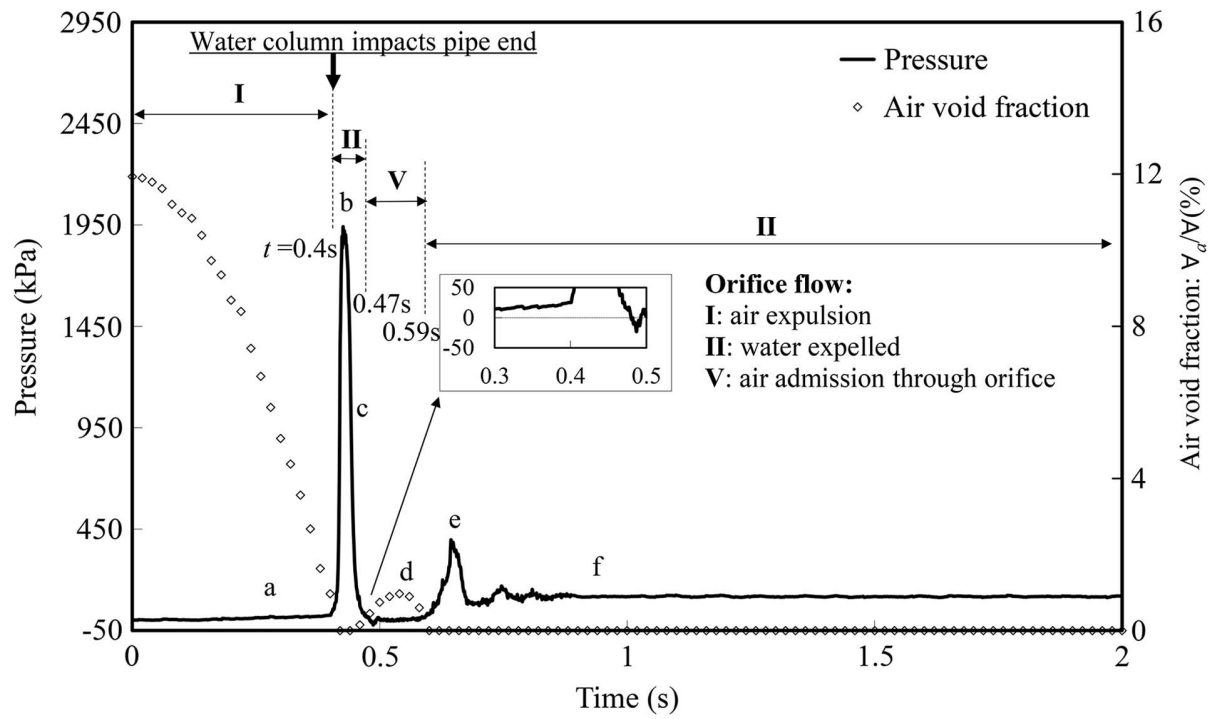

(g)

Fig. 5. Air-water pattern and transient pressure of Type 3 behavior during much air expulsion $\left(d / D=0.175, L_{a 0} / L=11.9 \%\right.$, and $H_{r}^{*} / H_{\mathrm{atm}}^{*}=2.18$ ): (a) $t=0.30 \mathrm{~s}$; (b) $t=0.41 \mathrm{~s}$; (c) $t=0.44 \mathrm{~s}$; (d) $t=0.54 \mathrm{~s}$; (e) $t=0.64 \mathrm{~s}$; (f) $t=0.94 \mathrm{~s}$; and (g) pressure oscillations at PT-1. 
Table 1. Range of orifice size for the three types of behavior

\begin{tabular}{|c|c|c|c|c|}
\hline Behavior & $\begin{array}{l}\text { Inlet head } \\
\left(H_{r}^{*} / H_{\mathrm{atm}}^{*}\right)\end{array}$ & $\begin{array}{l}\text { Air length } \\
L_{a 0} / L(\%)\end{array}$ & $\begin{array}{l}\text { Orifice size } \\
(d / D)\end{array}$ & Features \\
\hline Type 1 & 1.78 & $\begin{array}{l}11.9 \\
36.7 \\
72.8 \\
11.9 \\
36.7 \\
72.8 \\
11.9 \\
36.7 \\
72.8\end{array}$ & $\begin{array}{l}<0.075 \\
<0.075 \\
<0.075 \\
<0.075 \\
<0.08125 \\
<0.075 \\
<0.0875 \\
<0.0875 \\
<0.075\end{array}$ & $\begin{array}{l}\text { 1. Initial-air cushioning effect is dominant } \\
\text { 2. Maximum pressure is caused by the compression of the initial air before the water reaches } \\
\text { the pipe end } \\
\text { 3. Free and irregular air-water interface, rather than a vertical air-water interface } \\
\text { 4. Intermittent air expulsion } \\
\text { 5. Clear exhausting-air sound at the orifice }\end{array}$ \\
\hline Type 2 & 1.78 & $\begin{array}{l}11.9 \\
36.7 \\
72.8 \\
11.9 \\
36.7 \\
72.8 \\
11.9 \\
36.7 \\
72.8\end{array}$ & $\begin{array}{c}0.75-0.1125 \\
0.75-0.1125 \\
0.75-0.1125 \\
0.075-0.1 \\
0.08125-0.15 \\
0.075-0.125 \\
0.0875-0.1 \\
0.0875-0.125 \\
0.075-0.125\end{array}$ & $\begin{array}{l}\text { 1. Residual-air effect is significant } \\
\text { 2. Maximum pressure is caused by the residual air after the orifice is choked by water } \\
\text { 3. Free and irregular air-water interface, rather than a vertical air-water interface } \\
\text { 4. Intermittent air expulsion. } \\
\text { 5. Sonorous exhausting-air sound at the orifice }\end{array}$ \\
\hline Type 3 & 1.78 & $\begin{array}{l}11.9 \\
36.7 \\
72.8 \\
11.9 \\
36.7 \\
72.8 \\
11.9 \\
36.7 \\
72.8\end{array}$ & $\begin{array}{l}>0.1125 \\
>0.1125 \\
>0.1125 \\
>0.1 \\
>0.15 \\
>0.125 \\
>0.1 \\
>0.125 \\
>0.125\end{array}$ & $\begin{array}{l}\text { 1. Water-hammer effect is dominant } \\
\text { 2. Maximum pressure is caused by the filling water impacting onto the pipe end } \\
\text { 3. Nearly vertical air-water interface } \\
\text { 4. Complete expulsion of the initial entrapped air once } \\
\text { 5. Sonorous sound of water impacting onto the pipe end }\end{array}$ \\
\hline
\end{tabular}
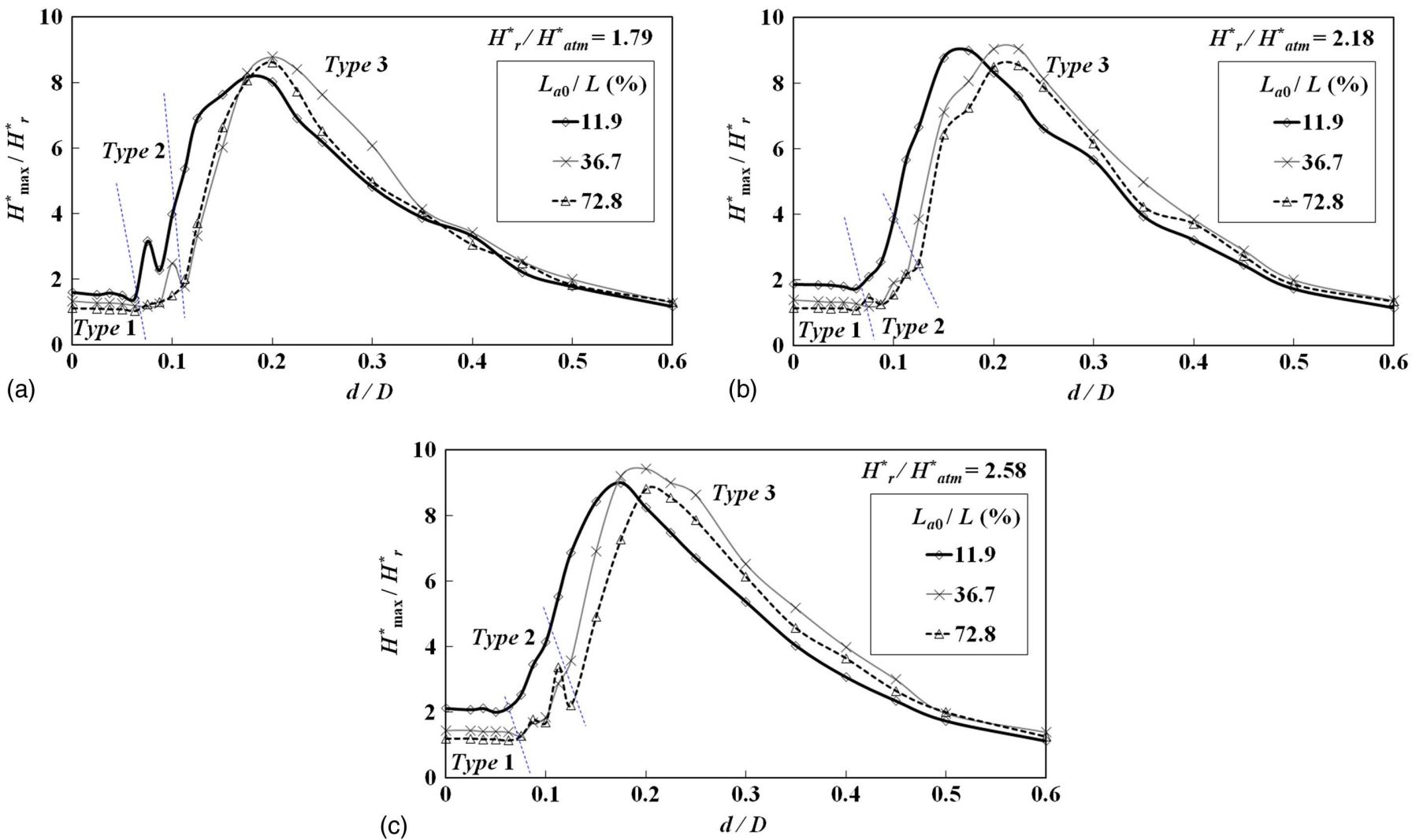

Fig. 6. Relation between maximum pressure at PT-1 and relative orifice size: (a) $H_{r}^{*} / H_{\mathrm{atm}}^{*}=1.79$; (b) $H_{r}^{*} / H_{\mathrm{atm}}^{*}=2.18$; and (c) $H_{r}^{*} / H_{\mathrm{atm}}^{*}=2.58$. 

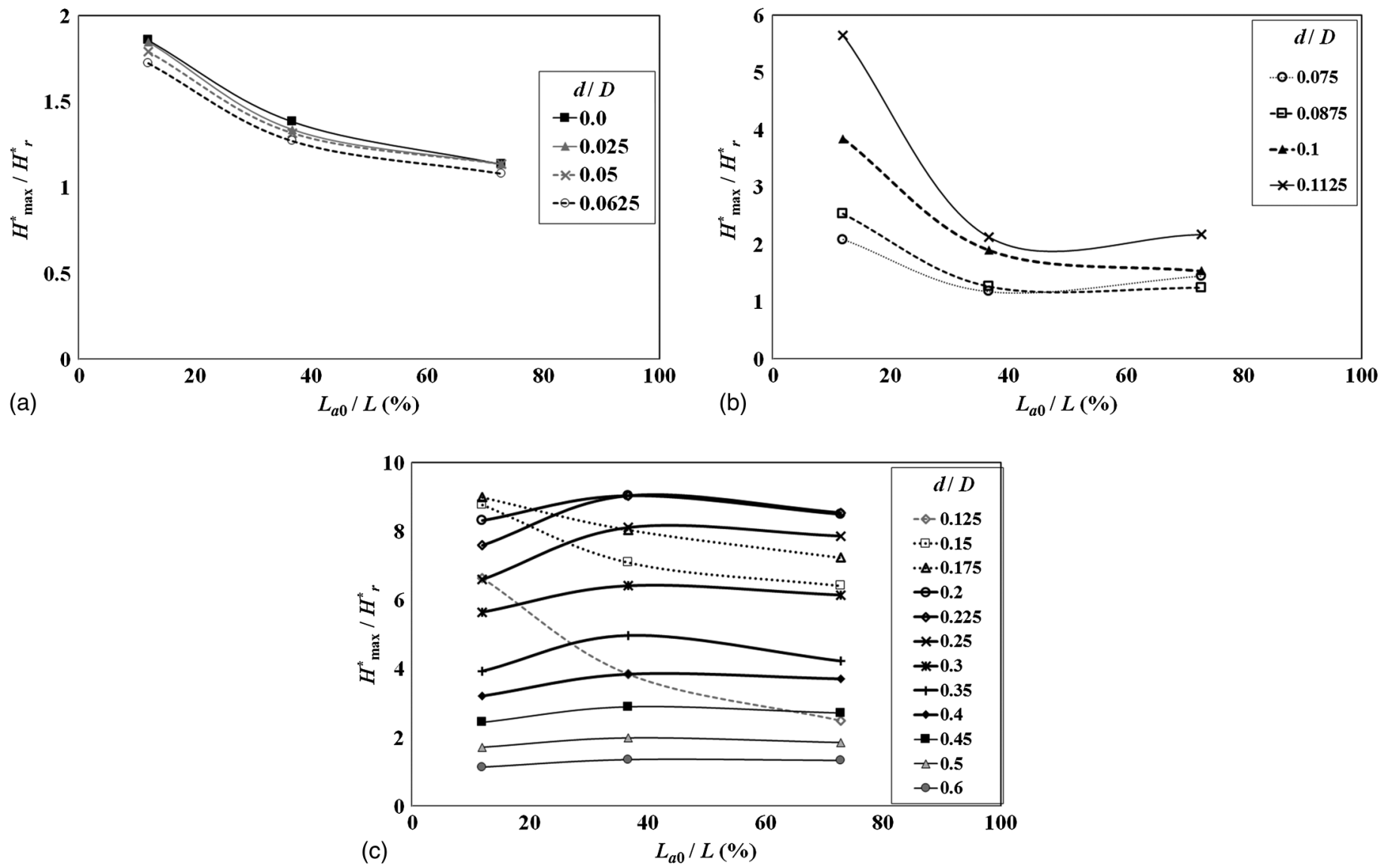

Fig. 7. Relation between the maximum pressure at PT-1 and initial-air length: (a) Type 1; (b) Type 2; and (c) Type 3.

velocity. The impact velocity is significantly associated with the air compression effect as well as the driving pressure accelerating the water column. A small air volume (air length) provides insufficient opportunity for the velocity to accelerate to high values, whereas a large air volume (air length) tends to intensify the air cushioning effect and increase the energy loss. Thus, the intermediate values of air volume are often most dangerous.

Figs. $8(\mathrm{a}-\mathrm{c})$ illustrate the effect of the inlet pressure on peak pressures, where $L_{a 0} / L=11.9 \%$. Based on the figures and those for other air lengths (not shown here), for Type 1 behavior, the ratio of the maximum pressure head to driving head $H_{\max }^{*} / H_{r}^{*}$ increases when the inlet pressure is larger. For Type 2 behavior, the data scatter of $H_{\max }^{*} / H_{r}^{*}$ is large, and there is no clear relationship between the driving pressure and peak pressures observed ahead of the orifice. For Type 3 behavior, when the orifice size is near the critical value $(d / D=0.2), H_{\max }^{*} / H_{r}^{*}$ increases under a larger inlet pressure. However, when the orifice size is far larger than the critical value $(d / D=0.2), H_{\max }^{*} / H_{r}^{*}$ nearly keeps constant, as shown in Fig. 8(c).

\section{Analytical Model of Simulating Pressure Oscillations}

In order to theoretically confirm the aforementioned interpretation of the experimental results, one analytical model is proposed to reproduce the three pressure-oscillation patterns discussed in the preceding "Experimental Observations and Results" section. On the basis of the numerical model of Zhou et al. (2019), the current model firstly considers the intermittent release-compressionexpansion characteristics of residual air. As before, the modeling assumes that there is a well-defined air-water interface and that the water-hammer wave speed is constant (Zhou et al. 2011, 2013a, 2019).

\section{Initial-Air Compression-Expulsion Stage (Types 1-3)}

The air-pocket behavior (Zhou et al. 2002a, 2019) is described by

$$
\frac{d H_{a}^{*}}{d t}=-k \cdot \frac{H_{a}^{*}}{\forall_{a}} \cdot \frac{d \forall_{a}}{d t}-k \cdot \frac{H_{a}^{*}}{\forall_{a}} \cdot Q_{a}
$$

where $H_{a}^{*}, \forall_{a}$, and $k=$ absolute pressure head, volume, and polytropic coefficient of the trapped air; $t=$ time; and $Q_{a}=$ volumetric flow discharge of the entrapped air through the pipe-end orifice.

When $H_{a}^{*} / H_{\mathrm{atm}}^{*}<1.89, Q_{a}$ can be expressed

$$
\begin{aligned}
Q_{a}= & C_{d} \cdot A_{0} \\
& \cdot \sqrt{2 \cdot g \frac{\rho}{\rho_{a}} \cdot \frac{n}{n-1} \cdot H_{a}^{*} \cdot\left(\frac{H_{\mathrm{atm}}^{*}}{H_{a}^{*}}\right)^{2 / n} \cdot\left(1-\left(\frac{H_{\mathrm{atm}}^{*}}{H_{a}^{*}}\right)^{(n-1) / n}\right)}
\end{aligned}
$$

where $C_{d}$ and $A_{0}=$ entrapped-air discharge coefficient and the orifice area of the pipe-end orifice; $g$ = gravitational acceleration; $\rho_{a}$ and $\rho=$ air and water density; and $n=$ polytropic coefficient for entrapped air flow through the pipe-end orifice.

In the case with sonic conditions $\left(H_{a}^{*} / H_{\mathrm{atm}}^{*} \geq 1.89\right)$, the pipeend orifice is choked, and the air flow through the orifice is independent of the outlet pressure 

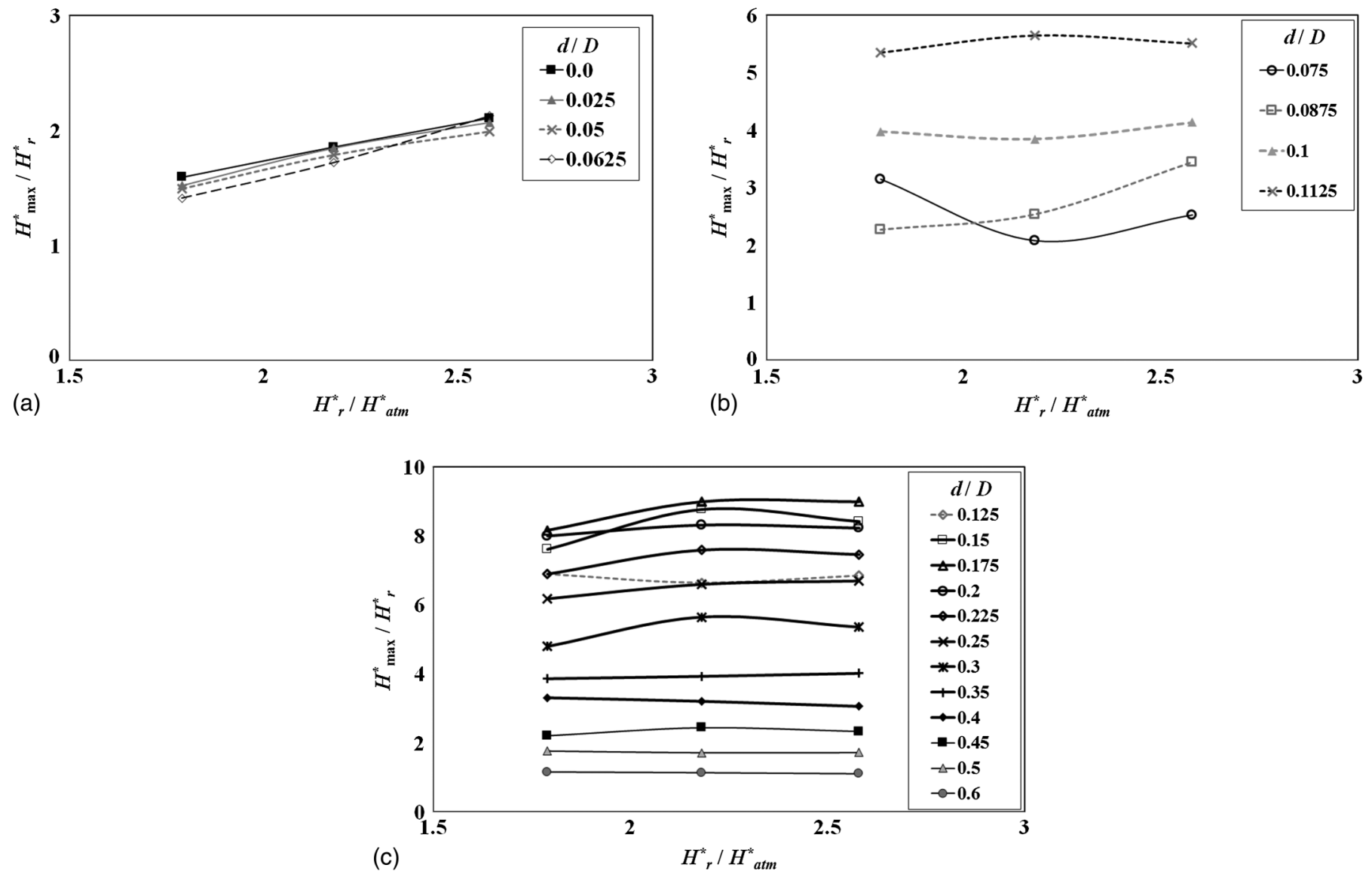

Fig. 8. Relation of the maximum pressure at PT-1 and inlet pressure: (a) Type 1; (b) Type 2; and (c) Type 3.

$$
Q_{a}=A_{0} \cdot C_{d} \cdot \sqrt{\left(\frac{\rho}{\rho_{a}} \cdot g \cdot H_{a}^{*}\right) \cdot\left[n \cdot\left(\frac{2}{n+1}\right)^{\frac{n+1}{n-1}}\right]}
$$

The movement and pressure of the moving air-water interface can be described by (Zhou et al. 2019)

$$
\begin{gathered}
L_{w}=L_{w 0}+\int_{0}^{t} V_{c} d t \\
H_{w c}^{*}=H_{a}^{*}
\end{gathered}
$$

where $L_{w}$ and $L_{w 0}=$ filling water length and its initial value; and $V_{c}$ and $H_{w c}^{*}=$ velocity and absolute piezometric head at the air-water interface, respectively.

\section{Residual-Air Compression-Expansion-Expulsion Stage (Types 1 and 2)}

For the behaviors of Types 1 and 2, after the water reaches the pipe end, residual air is entrapped within the end pipe section, and the end orifice may undergo four flow regimes: (I) air expulsion, (II) water expelled, (III) water with little air, and (IV) mist flow. The residual-air compression-expulsion-expansion process is still simulated by Eq. (2). The four flow regimes at the end orifice have different discharge coefficients $C_{d}$ (estimated from the experimental observations), and the transition time of the different flow regimes used in the analytic model was chosen to match the experimental results.

\section{Impacting Pressure Stage (Type 3)}

For Type 3, as the water column impacts the pipe end, the pipe flow becomes pure water flow, whereby the orifice remains open. The orifice's outlet boundary is always atmospheric. The continuity and momentum equations at the orifice are

$$
\begin{gathered}
Q_{P}=Q_{\text {orifice }} \\
H_{P}^{*}=H_{\mathrm{atm}}^{*}+\left(k_{\text {orifice }}-1\right) \frac{Q_{P}^{2}}{2 g A^{2}}+\frac{Q_{\text {orifice }}^{2}}{2 g A_{0}^{2}}
\end{gathered}
$$

where $A=$ pipe cross-sectional area; $Q_{P}$ and $Q_{\text {orifice }}=$ flow rate at the inlet and outlet of the orifice; $k_{\text {orifice }}=$ loss coefficient of the pipe-end orifice; and $H_{P}^{*}=$ absolute piezometric head at the upstream inlet of the pipe-end orifice.

Considering the elasticity and length variation of the filling water column, the continuity and momentum equations of the water can be solved by the fixed-grid methods of characteristics (MOC). The virtual-plug method neglecting inertia and head loss of a short water column $\Delta L_{w i}\left(0<\Delta L_{w i} \leq \Delta x\right.$ is recommended $)$ near the air-water interface (Zhou et al. 2019) is used to track the moving air-water interface. The water-hammer equation, the $C^{+}$equation, at the downstream end of the filling water is

$$
H_{P}^{*}=H_{A}^{*}+\frac{a}{2 g A}\left(Q_{A}-Q_{P}\right)-\frac{f \Delta x}{2 g A^{2}}\left|Q_{A}\right| Q_{P}
$$

where $\Delta x=$ MOC grid length; $a=$ wave speed; and $H_{A}^{*}$ and $Q_{A}=$ absolute pressure head and flow rate at the MOC node nearby the air-water interface. 

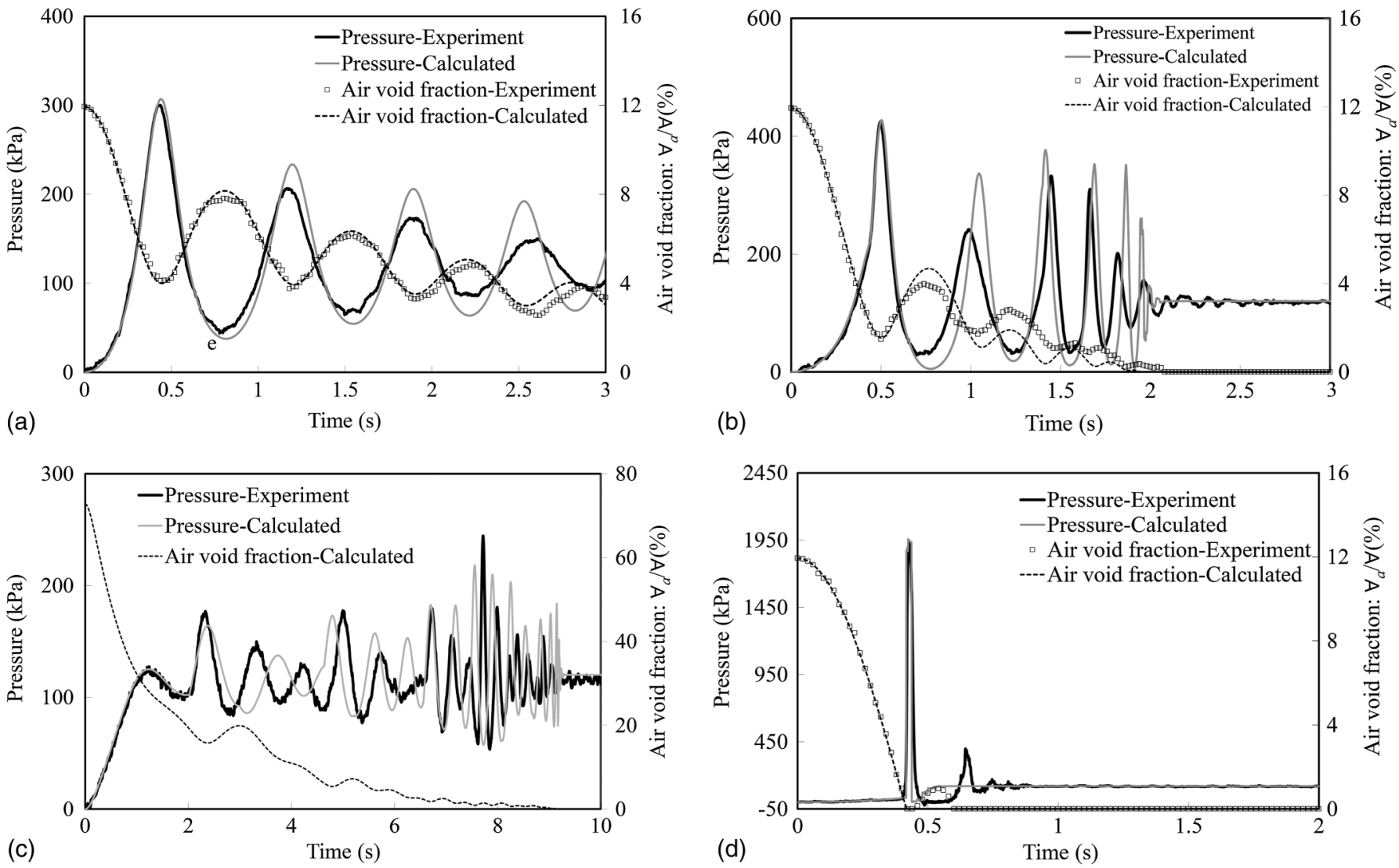

Fig. 9. Comparisons of the calculated and experimental pressure oscillations and air-volume variations: (a) $d / D=0.025, L_{a 0} / L=11.9 \%$, and $H_{r}^{*} / H_{\mathrm{atm}}^{*}=2.18$; (b) $d / D=0.0875, L_{a 0} / L=11.9 \%$, and $H_{r}^{*} / H_{\mathrm{atm}}^{*}=2.18$; (c) $d / D=0.0875, L_{a 0} / L=72.8 \%$, and $H_{r}^{*} / H_{\mathrm{atm}}^{*}=2.18$; and (d) $d / D=0.175, L_{a 0} / L=11.9 \%$, and $H_{r}^{*} / H_{\mathrm{atm}}^{*}=2.18$.

Tracking the moving air-water interface is realized by combining Eqs. (2), (5), (6), and (9) (Zhou et al. 2019). When the water filling column impacts the pipe end, the water-hammer pressure head can be calculated by combining Eqs. (7)-(9).

\section{Simulation Results}

In the simulations, MOC wave speed, discharge coefficient, pipe friction as measured in experiments, and polytropic coefficients $k=n=1.4$ for fast transients are used as input parameters. Moreover, for the residual-air compression-expansion-expulsion stage, transition times of different flow regimes used in the analytic model were chosen according to experimental results. Figs. 9(a-d) give a series of comparisons between computed and observed pressureoscillation patterns and transient-air volumes of Types $1-3$. In the cases of Figs. 9(a and b), $f=0.06, a=800 \mathrm{~m} / \mathrm{s}, C_{d}=0.82$ for air release, and transition times of different flow regimes are as shown in Figs. 2(g) and 3(h). In the case of Fig. 9(c), $f=0.08$, $a=800 \mathrm{~m} / \mathrm{s}, C_{d}=0.75$ for air release, and transition times of different flow regimes are as shown in Fig. 4(1). In the case of Fig. $9(\mathrm{~d}), f=0.03, a=850 \mathrm{~m} / \mathrm{s}$, and $C_{d}=0.75$ for air release. Fig. 10 displays the maximum pressure comparisons of the experimental and calculated results.

For Type 1 behavior, as shown in Fig. 9(a), the proposed model can well reproduce the experimental pressure history and the transient-air volume, especially for the first cycle and the frequency of oscillation. For Type 2, the proposed model can nicely reproduce the air pressure and air volume until the first residual-air stage ends, as well as the intermittent oscillation characteristics in the residual-air compression-expulsion stage [Figs. 9(b and c)]. For Type 3 behavior [Fig. 9(d)], the model can perfectly simulate the air-volume variations and pressure-oscillation pattern caused by air cushioning and the water impacting onto the pipe end. Fig. 10 indicates that the maximum pressures in all other experiments agree well with the numerical simulations.

The analytical study showed that the proposed mathematical model is adequate to investigate the rapid air expulsion. Importantly, the model also validates the analysis and explanations of the experimental investigations. In particular, the intermittent oscillation characteristics in the residual-air compression-expulsion

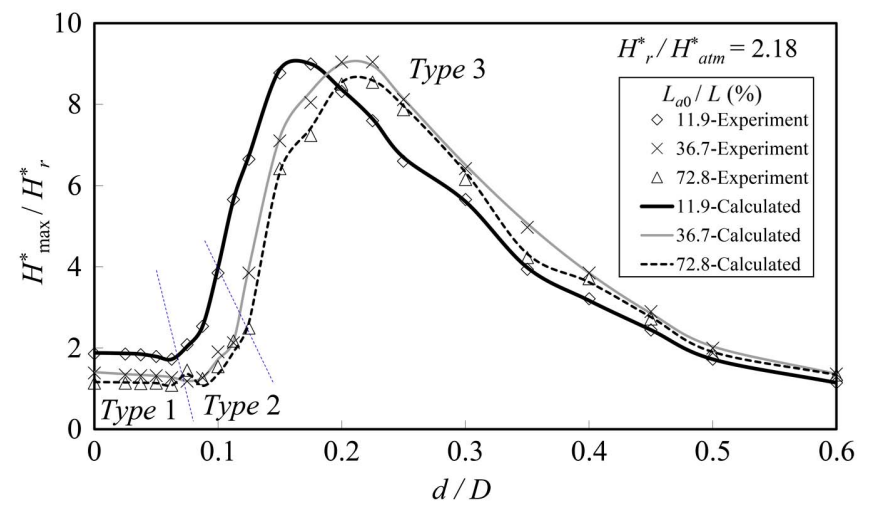

Fig. 10. Comparisons of the calculated and experimental maximum pressures. 
Table 2. Comparisons of the condition in previous and current experiments

\begin{tabular}{|c|c|c|c|c|c|}
\hline Source & Pipe material & $L(\mathrm{~m})$ & $D(\mathrm{~m})$ & Orifice $d / D$ & High-speed camera \\
\hline Martin and Lee $(2000,2012)$ and Lee (2005) & Plexiglas & 10.2 & 0.026 & 8 sizes: $0.06-0.5$ & No record \\
\hline Zhou et al. (2002a) & Steel & 10 & 0.035 & 12 sizes: $0-0.57$ & No record \\
\hline Zhou et al. (2002b) & Steel + Plexiglas & 10 & 0.035 & 5 sizes: $0-0.34$ & Yes \\
\hline Current work & Plexiglas & 8.862 & 0.04 & 21 sizes: $0-0.6$ & Yes \\
\hline
\end{tabular}

stage of Types 1 and 2, and the water impact onto the pipe end of Type 3, are explained well.

\section{Comparisons with Previous Work}

Compared with the earlier investigations of Zhou et al. (2002a, b), Martin and Lee (2000, 2012), and Lee (2005), the more complete characteristics of pressure oscillations associated with the orifice size are revealed by using a more refined range of orifice sizes as indicated in Table 2. Especially, the region with $d / D$ ranging from 0.75 to 1.75 involving three complicated types of pressure oscillations (Fig. 6) is more intensively investigated in this work. The synchronous relations among the transient pressures, airvolume variations, and orifice flow regimes obtained by processing the high-quality images of air-water interaction, and the air-water interaction during rapid pipe filling are first investigated in this work. Moreover, the experimental pressure oscillations and airvolume variations can be well reproduced by the analytical model considering the intermittent release-compression-expansion characteristics of residual air and the impacting water-hammer, which confirms the experimental analysis and explanation in the current work. The different experimental conditions are listed in Table 2.

\section{Pressure-Oscillation Patterns}

More detailed pattern characteristics of pressure oscillations are revealed here. Types 1 and 3 regimes in this work are similar to Types 1 and 3 regimes identified by Zhou et al. (2002a, b), as shown in Fig. 11(a). However, the current Type 2 behavior (dominated by residual-air effects) differs from the descriptions of Type 2 (mitigated water-hammer effect) of Zhou et al. (2002a, b). As described by Zhou et al. (2002a, b), the maximum pressure of Type 2 behavior is caused by the water hammer immediately after the release of the last entrapped air pocket [Fig. 11(a)].
In the Type 2 behavior of this work, the highest peak is due to the compression of residual air, not due to the initial-air compression or the water impacting onto the pipe end. As shown in Figs. 3 and 4, the maximum pressure may arise at the first residual-air stage or at any other subsequent residual-air stage. Zhou et al. (2002a, b) only observed one pattern of Type 2 [Fig. 11(a)], which is similar to that of the dominant later-residual-air situation in Fig. 4(1) in this work, although Zhou et al. (2002a, b) thought that the maximum pressure is caused by the water-hammer after the release of the last air pocket rather than the residual air.

Compared with the work of Martin and Lee $(2000,2012)$ and Lee (2005), the critical region $(d / D=0.75-1.75)$ involving three types of pressure oscillations (Fig. 6), is more intensively investigated in this work by using seven orifice sizes (Fig. 6) instead of only one size [Fig. 12(b)]. In particular, the high-speed highresolution camera is used to record dynamic information on the air-water interaction profiles, air-volume variations, and the orifice flow regimes, which are extremely significant to distinguish the effecting factor and confirm the transient mechanisms.

Importantly, as shown in Fig. 12(a), the pressure oscillations for a medium orifice size $d / D=0.244$ reported by Lee (2005) and Martin and Lee (2012) are similar to Type 3 behavior in this paper [Fig. 5(g)] and to Type 3 of Zhou et al. (2002a) [Fig. 11(a)], although Lee (2005) and Martin and Lee (2012) believed that the maximum pressures are associated with rapid compression of the small remaining amount of air rather than a traditional waterhammer impact.

\section{Effects of the Orifice Size on the Maximum Pressure}

Compared with the works of Zhou et al. (2002a, b), Martin and Lee (2000, 2012), and Lee (2005), this work reveals more complete diagrams of the relations between the orifice size and the peak pressure, as shown in Figs. 6, 11(b), and 12(b). Importantly, the new results are not conflicting with those of Zhou et al. (2002a, b),
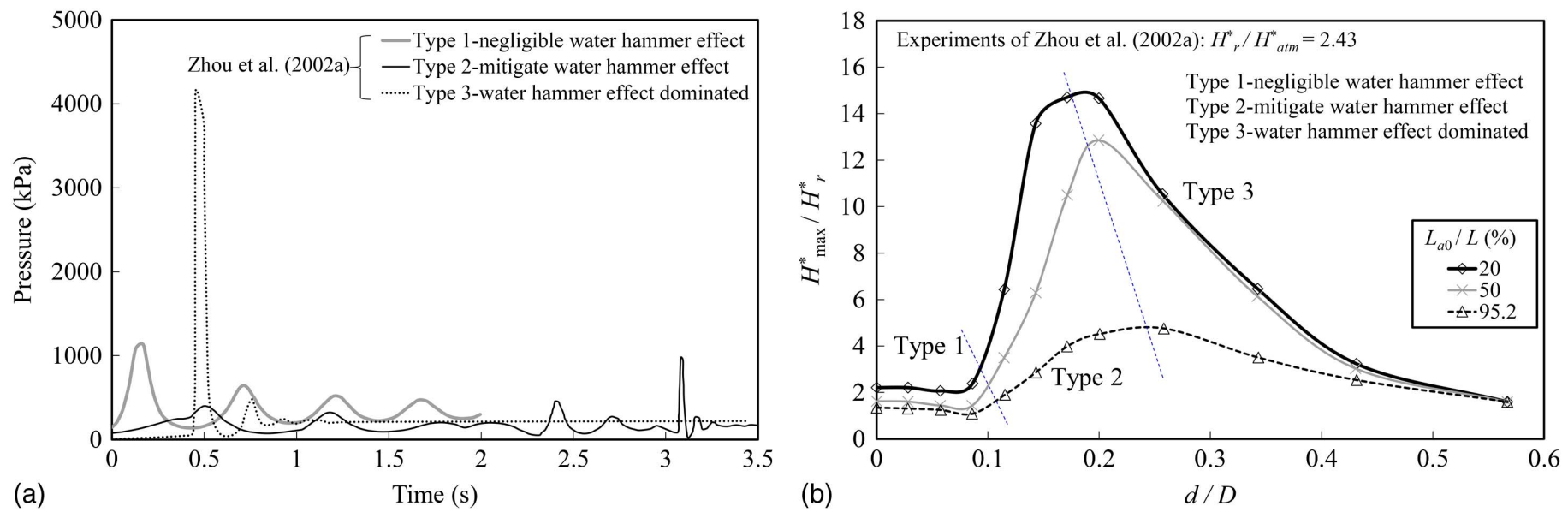

Fig. 11. Experimental pressure results: (a) pressure-oscillation patterns; and (b) maximum pressures. (Data from Zhou et al. 2002a.) 

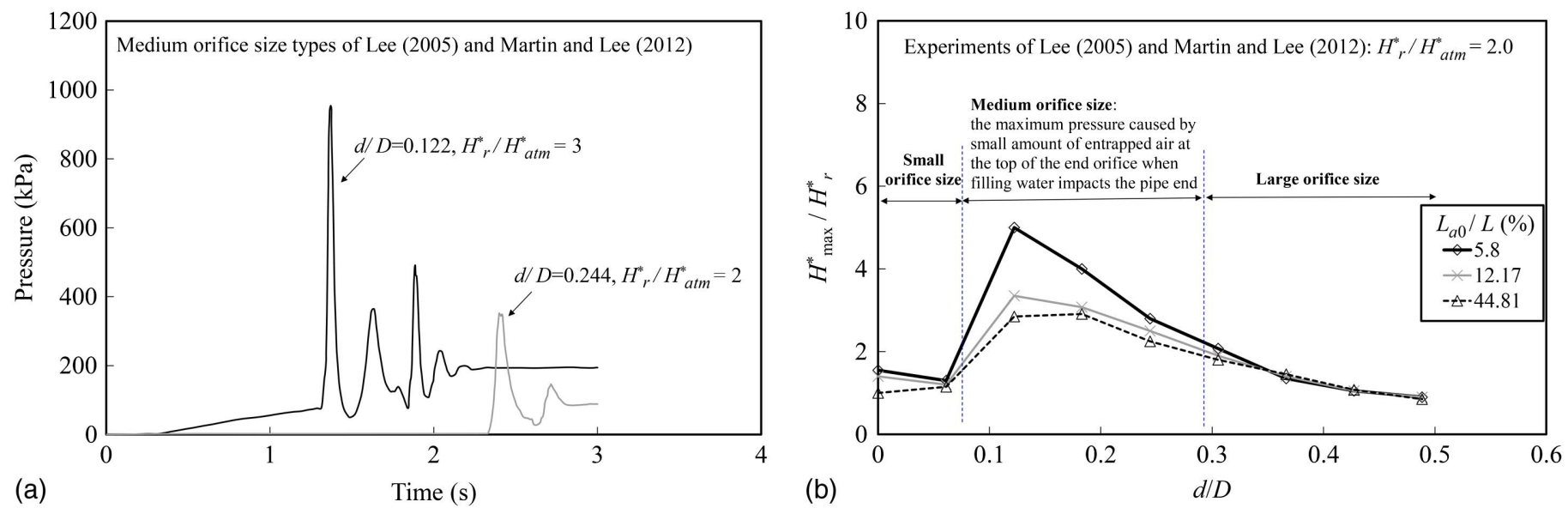

Fig. 12. Experimental pressure results: (a) pressure-oscillation patterns; and (b) maximum pressures. (Data from Lee 2005; Martin and Lee 2012.)

Martin and Lee (2000, 2012), and Lee (2005), which can also be observed in this work. Fig. 6 also shows that Type 2 behavior is observed for a short range of $d / D$, and it is a transition between the two major types previously identified by Zhou et al. (2002a, b), Martin and Lee (2000, 2012), and Lee (2005).

\section{Conclusions}

Transient air expulsion through an orifice in a rapidly filling horizontal pipeline has been investigated experimentally and analytically. The main conclusions are as follows:

1. Rapid air expulsion due to water filling a horizontal pipeline tends to undergo several quite distinct stages. Stage 1 involves the initial-air compression and expulsion before the water column reaches the pipe end. For small orifices, Stage 2(a) is associated with oscillation of the residual air; by contrast, with larger orifices, Stage 2(b) is associated with a sudden impacting water-hammer pressure.

2. Three types of pressure-oscillation patterns were observed, depending on the orifice size. With small orifices, Type 1 behavior arises: the initial-air cushioning effect is dominant and the maximum pressure caused by it ranges from 1.5 to 2 times the inlet pressure. With slightly larger orifices, Type 2 behavior occurs, wherein the dominant residual-air effect causes a longer pressure oscillation and a higher peak pressure (up to four times the inlet pressure). When the orifice size is further increased, Type 3 behavior appears: the air effects are less profound, and the water-hammer pressure (up to nine times the inlet pressure) in stage 2(b) is dominant. As the orifice size increases, for Type 1 behavior, the maximum pressure decreases; for Type 2 behavior, there is no obvious relationship between the orifice size and the peak pressure; for Type 3 behavior, the maximum pressure is observed to increase sharply and then gradually decrease far from the critical $d / D$ value of 0.2 .

3. The mathematical model accurately reproduces the measured pressure oscillations and air-volume variations in the three types of behavior, which helps to independently confirm both the model and the experimental observations.

4. Types 1 and 3 pressure-oscillation patterns in this work are similar to Types 1 and 3 behavior identified by Zhou et al. (2002a, b) as well as those reported by Martin and Lee (2000, 2012) and Lee (2005). For the new Type 2 behavior, the dominant residual-air effect leads to severe pressures, and the maximum pressure may arise either at the first residual-air stage or at any other subsequent residual-air stage.

\section{Data Availability Statement}

Some or all data, models, or code that support the findings of this study are available from the corresponding author upon reasonable request.

\section{Acknowledgments}

The authors gratefully acknowledge the financial support for this research from the National Natural Science Foundation of China (Grant Nos. 51679066 and 51839008), the Fundamental Research Funds for the Central Universities (Grant No. 2018B43114), Fok Ying Tong Education Foundation (Grant No. 161068), and the China Scholar Council (File No. 201806715024). A. Bergant acknowledges the support of Slovenian Research Agency (Project L2-1825 and Programme P2-0162).

\section{Notation}

The following symbols are used in this paper:

$A=$ cross-sectional area of pipe;

$A_{0}=$ orifice area;

$C_{d}=$ discharge coefficient;

$D=$ pipe diameter;

$d=$ orifice diameter;

$g=$ gravitational acceleration;

$H_{a}^{*}$ and $H_{a 0}^{*}=$ absolute pressure head of entrapped air and its initial value;

$H_{\mathrm{atm}}^{*}=$ absolute atmospheric pressure head;

$H_{\max }^{*}=$ maximum absolute pressure head;

$H_{P}^{*}=$ absolute piezometric head at the upstream inlet of the orifice;

$H_{r}$ and $H_{r}^{*}=$ upstream inlet head (relative pressure) and its absolute value;

$H_{w c}^{*}=$ absolute piezometric head at the air-water interface;

$k=$ polytropic coefficient of entrapped air pocket;

$k_{\text {orifice }}=$ loss coefficient; 


\section{$L=$ pipe length;}

$L_{a}$ and $L_{a 0}=$ entrapped air length and its initial value;

$L_{w}$ and $L_{w 0}=$ filling water length and its initial value;

$n=$ polytropic coefficient for compressible flow through an orifice;

$P_{r}$ and $P_{r}^{*}=$ upstream inlet relative pressure and its absolute value;

$Q_{a}=$ volumetric air flow discharge through the orifice;

$Q_{\text {orifice }}=$ flow rate at the outlet of the orifice;

$Q_{P}=$ flow rate at the inlet of the orifice;

$t=$ time;

$V_{c}=$ velocity at the air-water interface;

$\rho=$ water density;

$\rho_{a}=$ air density; and

$\forall_{a}$ and $\forall_{a 0}=$ volume of entrapped air and its initial value.

\section{References}

Albertson, M. L., and J. Andrews. 1971. "Transients caused by air release." In Control of flow in closed conduits, edited by J. P. Tullis, 315-340. Fort Collins, CO: Colorado State Univ.

Bergant, A., A. Tijsseling, Y. Kim, U. Karadžić, L. Zhou, M. Lambert, and A. Simpson. 2018. "Unsteady pressure influenced by trapped air pocket in liquid-filled pipelines." Strojniški vestnik J. Mech. Eng. 64 (9): 501-512. https://doi.org/10.5545/sv-jme.2018.5238.

Bucur, D. M., G. Dunca, and M. J. Cervantes. 2017. "Maximum pressure evaluation during expulsion of entrapped air from pressurized pipelines." J. Appl. Fluid Mech. 10 (1): 11-20. https://doi.org/10.18869 /acadpub.jafm.73.238.26313.

Lee, N. H. 2005. "Effect of pressurization and expulsion of entrapped air in pipelines." Doctoral dissertation, School of Civil and Environmental Engineering, Georgia Institute of Technology.

Li, L., and D. Z. Zhu. 2018. "Modulation of the transient pressure by an air pocket in a horizontal pipe with an end orifice." Water Sci. Technol. 77 (10): 2528-2536. https://doi.org/10.2166/wst.2018.213.

Martin, C. S. 1976. "Entrapped air in pipelines." In Proc., 2nd Int. Conf. on Pressure Surges, 15-27. London: British Hydromechanics Research Association.
Martin, C. S., and N. Lee. 2012. "Measurement and rigid column analysis of expulsion of entrapped air from a horizontal pipe with an exit orifice." In Proc., 11th Int. Conf. on Pressure Surges, 537-542. Bedfordshire, UK: BHR Group.

Martin, C. S., and N. H. Lee. 2000. "Rapid expulsion of entrapped air through an orifice." In Proc., 8th Int. Conf. on Pressure Surges-Safe Design and Operation of Industrial Pipe Systems, 125-132. Bury St. Edmunds, UK: BHR Group.

Tijsseling, A. S., Q. Hou, and Z. Bozkuş. 2019. "Rapid liquid-filling of a pipe with venting entrapped-gas: Analytical and numerical solutions." J. Pressure Vessel Technol. ASME 141 (4): 041301. https://doi.org/10 $.1115 / 1.4043321$.

Wright, S. J., J. W. Lewis, and J. G. Vasconcelos. 2011. "Geysering in rapidly filling storm-water tunnels." J. Hydraul. Eng. 137 (1): 112-115. https://doi.org/10.1061/(ASCE)HY.1943-7900.0000245.

Zhou, F., F. E. Hicks, and P. M. Steffler. 2002a. "Observations of air-water interaction in a rapidly filling horizontal pipe." J. Hydraul. Eng. 128 (6): 635-639. https://doi.org/10.1061/(ASCE)0733-9429(2002) 128:6(635).

Zhou, F., F. E. Hicks, and P. M. Steffler. 2002b. "Transient flow in a rapidly filling horizontal pipe containing trapped air." J. Hydraul. Eng. 128 (6): 625-634. https://doi.org/10.1061/(ASCE)0733-9429(2002) 128:6(625).

Zhou, L., D. Liu, and B. Karney. 2013a. "Investigation of hydraulic transients of two entrapped air pockets in a water pipeline." J. Hydraul. Eng. 139 (9): 949-959. https://doi.org/10.1061/(ASCE)HY.1943-7900 .0000750 .

Zhou, L., D. Liu, B. Karney, and P. Wang. 2013b. "Phenomenon of white mist in pipelines rapidly filling with water with entrapped air pockets." J. Hydraul. Eng. 139 (10): 1041-1051. https://doi.org/10.1061/(ASCE) HY.1943-7900.0000765.

Zhou, L., D. Liu, B. Karney, and Q. Zhang. 2011. "Influence of entrapped air pockets on hydraulic transients in water pipelines." J. Hydraul. Eng. 137 (12): 1686-1692. https://doi.org/10.1061/(ASCE)HY.1943-7900 .0000460 .

Zhou, L., T. Pan, H. Wang, D. Liu, and P. Wang. 2019. "Rapid air expulsion through an orifice in a vertical water pipe." J. Hydraul. Res. 57 (3): 307-317. https://doi.org/10.1080/00221686.2018.1475427.

Zhou, L., H. Wang, B. Karney, D. Liu, P. Wang, and S. Guo. 2018. "Dynamic behavior of entrapped air pocket in a water filling pipeline." J. Hydraul. Eng. 144 (8): 04018045. https://doi.org/10.1061/(ASCE) HY.1943-7900.0001491. 